University of Louisville

ThinkIR: The University of Louisville's Institutional Repository

$12-2015$

\title{
Synthesis and functional evaluation of peptide modified poly (lactic-co-glycolic acid) nanoparticles to inhibit porphyromonas gingivalis biofilm formation.
}

Paridhi Kalia

Follow this and additional works at: https://ir.library.louisville.edu/etd

Part of the Biomedical Engineering and Bioengineering Commons, Nanomedicine Commons, Oral Biology and Oral Pathology Commons, and the Periodontics and Periodontology Commons

\section{Recommended Citation}

Kalia, Paridhi, "Synthesis and functional evaluation of peptide modified poly (lactic-co-glycolic acid) nanoparticles to inhibit porphyromonas gingivalis biofilm formation." (2015). Electronic Theses and Dissertations. Paper 2302.

https://doi.org/10.18297/etd/2302

This Master's Thesis is brought to you for free and open access by ThinkIR: The University of Louisville's Institutional Repository. It has been accepted for inclusion in Electronic Theses and Dissertations by an authorized administrator of ThinkIR: The University of Louisville's Institutional Repository. This title appears here courtesy of the author, who has retained all other copyrights. For more information, please contact thinkir@louisville.edu. 


\title{
SYNTHESIS AND FUNCTIONAL EVALUATION OF PEPTIDE MODIFIED POLY (LACTIC-CO-GLYCOLIC ACID) NANOPARTICLES TO INHIBIT \\ PORPHYROMONAS GINGIVALIS BIOFILM FORMATION
}

By

Paridhi Kalia

B.D.S., Bhavnagar University, 2012

\author{
A Thesis \\ Submitted to the Faculty of the \\ School of Dentistry of the University of Louisville \\ in Partial Fulfillment of the Requirements \\ for the Degree of \\ Master of Science \\ in Oral Biology \\ Department of Oral Immunology and Infectious Disease \\ School of Dentistry \\ University of Louisville \\ Louisville, KY
}

December 2015 
Copyright by Paridhi Kalia in 2015

All Rights Reserved 



\section{SYNTHESIS AND FUNCTIONAL EVALUATION OF PEPTIDE MODIFIED POLY (LACTIC-CO-GLYCOLIC ACID) NANOPARTICLES TO INHIBIT PORPHYROMONAS GINGIVALIS BIOFILM FORMATION}

By

Paridhi Kalia, B.D.S., Bhavnagar University, 2012

Thesis Approved on

December 01, 2015

By the following Thesis Committee:

\section{Dr. Donald R. Demuth, Ph.D. Thesis Director}
Dr. Jill M. Steinbach-Rankins, Ph.D. Co- Mentor

Dr. Richard J. Lamont, Ph.D. 


\section{DEDICATION}

To my brother Akshay Kalia 


\section{ACKNOWLEDGEMENTS}

I am deeply appreciative of a lot of individuals who have supported my work and continually encouraged me through the writing of this thesis. Without their time, attention, encouragement, thoughtful feedback, and patience, I would not have been able to see it through.

Firstly, I would like to thank my research mentors, Dr. Donald Demuth and Dr. Jill Steinbach for their guidance, encouragement, and support. They have both been outstanding mentors, and I have cherished working in both their labs. Furthermore, I thank them for teaching me all about self-discipline in laboratory work and written scientific communication. I would also like to thank my other committee member, Dr. Richard Lamont and the Masters in Oral Biology Program Director, Dr. Douglas Darling for their encouragement and assistance over the past two years.

I would like to thank my parents, Shiv Kamal Kalia and Dr. Kiran Kalia, who have been sources of encouragement and inspiration to me throughout my life, a very special thank you for providing me valuable insights in my experiments.

Finally, I would like to thank my brother, Akshay Kalia for encouraging and motivating me to pursue my dreams. I thank him for the myriad of ways in which, throughout my life, he has actively supported me in my determination to find and realize my potential

Special thanks to my friends, Shyamali Sahu, Rohan Verma, Chitwan Pal Singh Sachdev, Priya Sinha, Risha Khan, Neelima Cherukumalli, Emeri Jimenez-Flores, The editing advice, general help and friendship were all greatly appreciated. 


\section{ABSTRACT \\ SYNTHESIS AND FUNCTIONAL EVALUATION OF PEPTIDE-MODIFIED POLY(LACTIC-CO-GLYCOLIC ACID) NANOPARTICLES TO INHIBIT PORPHYROMONAS GINGIVALIS BIOFILM}

Paridhi Kalia

Dec 01, 2015

Periodontal disease is an oral inflammatory disorder that afflicts roughly $46 \%$ of the adults in the U.S. Currently, treatment of periodontal disease involves the removal of plaque from the gingival pocket (with possible antibiotic treatment) and if necessary, gingival surgery. To our knowledge, no therapeutic approach exists that promotes hostbiofilm homeostasis by limiting pathogen recolonization of the oral cavity after prophylaxis or treatment. The interaction of the pathogen Porphyromonas gingivalis with commensal streptococci is critical for initiation of periodontitis and represents a target for limiting $P$. gingivalis colonization of the oral cavity. Previous studies showed that a synthetic peptide (BAR) derived from antigen I/II protein of Streptococcus gordonii potently inhibited $P$. gingivalis adherence to streptococci. However, BAR was less effective in preventing $P$. gingivalis adherence in a more complex three species biofilm model, suggesting that the potency of BAR against complex biofilms may be reduced. This study focuses on designing surface-modified poly(lactic-co-glycolic acid; PLGA) nanoparticles (NPs) that are functionalized with BAR to increase its inhibitory potency by multivalent binding with $P$. gingivalis. Biotinylated BAR was conjugated to the surface of avidin-palmitylated PLGA NPs. We generated NPs with particle size of 100 
$\pm 28 \mathrm{~nm}$ and Zeta Potential of $-12 \mathrm{mV}$. The surface modification of avidin-NPs with BAR was examined using two approaches. Comparing the binding of biotin-PEG FITC with avidin-NPs and avidin-NPs that were reacted with biotinylated BAR showed that BAR binding efficiency was approximately 98\%. In addition, reacting avidin-NPs with fluorescently labeled BAR showed that a concentration of $37.1 \mathrm{nmol}$ BAR/mg NPs resulted in maximal BAR binding. We also showed that BAR-NPs bound to $P$. gingivalis in a dose-dependent manner and significantly $(\mathrm{P}<0.01)$ inhibited $P$. gingivalis/S. gordonii biofilm formation $(50 \%$ inhibitory concentration $=0.29 \mu \mathrm{M})$ making it 4.5 times more potent than soluble BAR. Together this platform represents a potential therapeutic approach to effectively target an initial interaction involved in $P$. gingivalis colonization of the oral cavity. 


\section{TABLE OF CONTENTS}

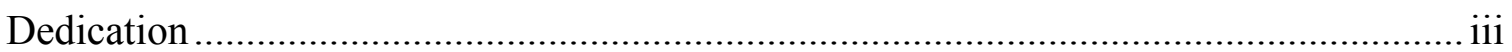

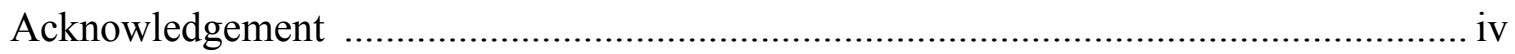

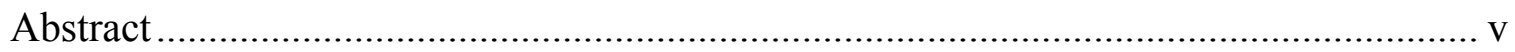

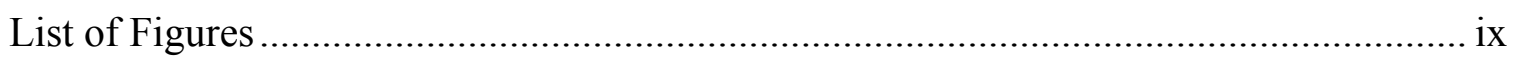

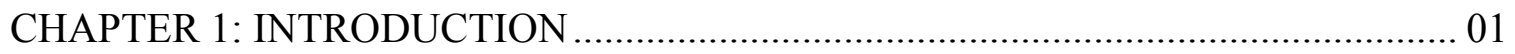

CHAPTER 2: HYPOTHESIS AND SPECIFIC AIMS ............................................. 12

CHAPTER 3: MATERIALS AND METHODS ............................................................14

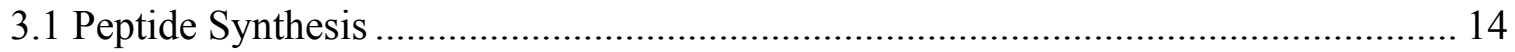

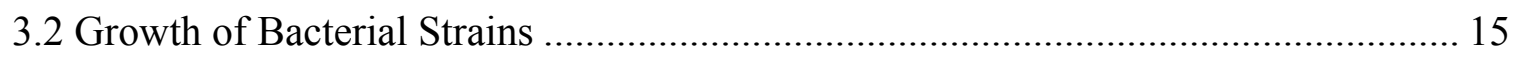

3.3 Synthesis of Avidin-Palmitate Conjugates ........................................................... 15

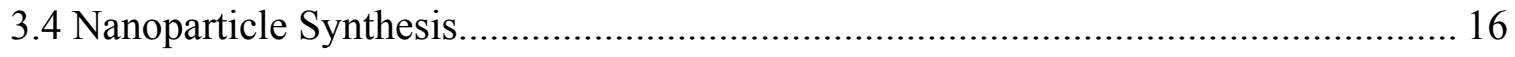

3.5 Functional Characterization ............................................................................... 18

3.5.1 Indirect Characterization: Biotin-PEG-FITC Reaction ....................................... 18

3.5.2 Direct Characterization: Binding of Fluorescently-Labeled BAR to Avidin-NPs .. 20

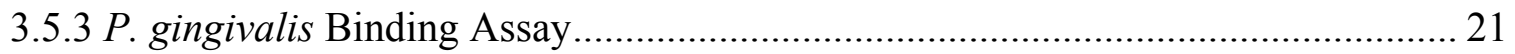




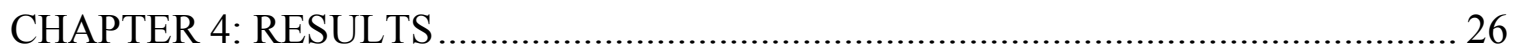

4.1 Nanoparticle Synthesis and Characterization ................................................. 26

4.2 Surface Modification Efficacy and Functionality of PLGA-NPs ............................ 28

4.3 Quantification of Total Biotin Binding Sites.................................................... 28

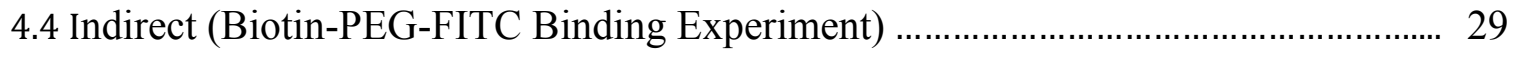

4.5 Direct (Fluorescently Labeled BAR Binding Experiment) .................................. 30

4.6 BAR Inhibits Formation of $P$. gingivalis Biofilms........................................... 33

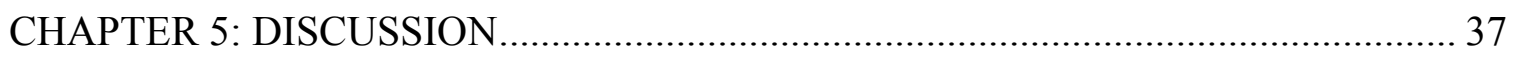

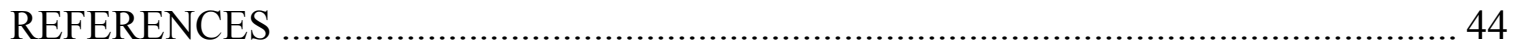

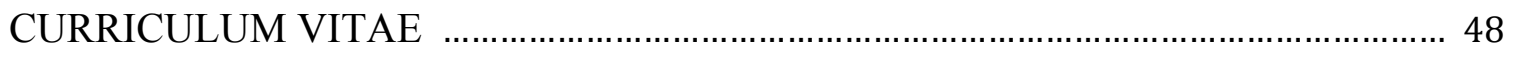




\section{LIST OF FIGURES}

Figure 1 Schematic of Dental Plaque Formation ..................................................... 4

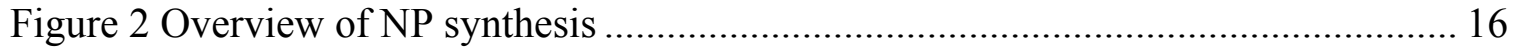

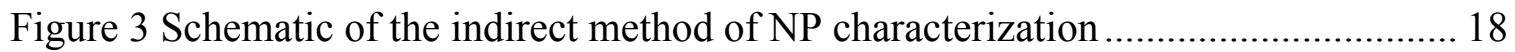

Figure 4: Schematic of the direct characterization method. ....................................... 20

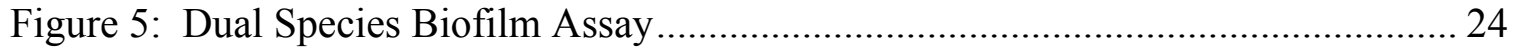

Figure 6 : (A) SEM images of unmodified and BAR-NPs and their corresponding distribution of NP diameter.

(B) DLS values of NP hydrodynamic diameters.

(C) Zeta potential values of all NPs....................................................... 28

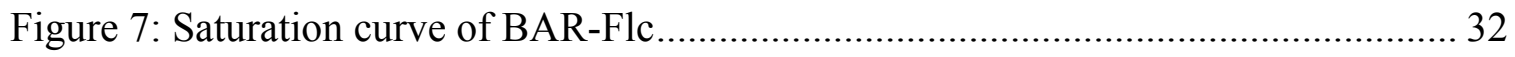

Figure 8: Dose dependent binding of BAR-NPs with encapsulated C6 to P. gingivalis.. 32

Figure 9: Comparison of BAR and BAR-NP inhibition of $P$. gingivalis and $S$. gordonii

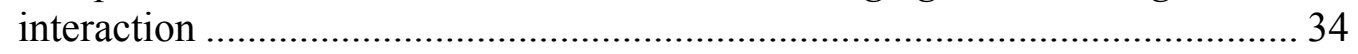

Figure 10: P. gingivalis Inhibition plot of BAR-Flc and soluble BAR ......................... 35 


\section{CHAPTER 1}

\section{INTRODUCTION}

According to the World Oral Report 2003, periodontal disease is among the most common microbial disease affecting the adult population worldwide and is one of the major oral health care problems globally. Periodontal disease is prevalent and occurs in $46 \%$ of adults in the U.S ${ }^{16,24,15}$ Severe disease (subgingival pocket depths $>6 \mathrm{~mm}$ ) occurs in $9 \%$ of U.S. adults ${ }^{1}$ and $11.2 \%$ of adults worldwide ${ }^{16,24}$. Domestically, this correlates to annual expenditures for the treatment and prevention of periodontal disease in excess of 14 billion dollars ${ }^{16,15}$.

Periodontal disease is an oral inflammatory disorder that is initiated by microbial biofilms that form in the subgingival pocket leading to severe chronic inflammation characterized by alveolar bone resorption and subsequent tooth loss ${ }^{21}$. The milder form of disease starts with gingival inflammation, termed as gingivitis. Gingivitis, if left untreated can lead to a more severe form of periodontal disease characterized by clinical attachment loss, termed as periodontitis ${ }^{21}$.

\section{Role of Periodontal Pathogens}

The resident organisms of dental plaque play a significant role in the onset and advancement of periodontal disease. ${ }^{8,22}$ Over 700 different species of bacteria colonize and interact with each other to form dental plaque ${ }^{14}$. In a state of health, the oral cavity is comprised of benign commensals, majorly Actinomyces and streptococci ${ }^{22}$. However 
shifts in population, mainly gram-negative anaerobes may orchestrate periodontal disease. Even if these organisms are present in low abundance, they have they have the ability to remodel their local environment from a naturally benign microbiota to a dysbiotic environment ${ }^{9,10,22}$. Among such organisms, Porphyromonas gingivalis have gained much attention, $9,10,18$.

P. gingivalis colonizes in the subgingival plaque, but before transitioning in its primary niche, it first establishes itself in a relatively aerobic environment, where it interacts with commensal streptococci gordonii ${ }^{12,28}$. The interaction is mediated by two receptor-ligand pairs namely the the long and short fimbriae of $P$. gingivalis ${ }^{4,12,28}$. The long fimbrial subunit protein (FimA) interacts with cell surface glyceraldehyde-3phosphate dehydrogenase of $S$. gordonii ${ }^{8,9,10,12}$ whereas the minor fimbrial protein in $P$. gingivalis, interacts with streptococcal $\mathrm{SspB}^{5,10}$. SspB belongs to the cell surface protein in the antigen I/II protein that are present on the cell surface of nearly all the species of streptococci. ${ }^{8,910,12}$. Prior studies suggested that purified P. gingivalis showed binding specificity with streptococci gordonii primarily because the Mfa1 of P. gingivalis did not interact with antigen I/II of S. mutans ${ }^{10}$. Furthermore, studies by Demuth et al. ${ }^{12}$ and Cook et al. ${ }^{6}$ showed that the interaction of $P$. gingivalis and $S$. gordonii mediated by Mfa1-SspB represented an essential initial event that facilitates $P$. gingivalis colonization in the oral cavity,9,10,18,28,36.

\section{Dental Plaque Formation and Disease Pathogenesis}

Dental plaque is a specific and highly variable structural entity consisting of microorganisms and their products embedded in a highly organized intercellular 
matrix $^{34,38}$. It represents a community of microorganisms involved in a wide range of physical, metabolic and molecular interactions organized in an extracellular matrix ${ }^{32,33,34}$. This environment provides advantages to the organisms such as a broader habitat range for growth and enhanced resistance to antimicrobial agents and host defenses ${ }^{32,33,34}$. Understanding the formation and progression of dental plaque and hence, periodontal disease etiology will aid in developing novel therapies to prevent and treat periodontal diseases $^{32}$.

The process of dental plaque formation is complex, and involves several distinct phases, beginning with bacterial attachment to the tooth surface via the salivary pellicle that forms immediately following tooth eruption or tooth cleaning ${ }^{13}$. Following initial

attachment, adherent bacteria begin to proliferate and form microcolonies ${ }^{14,31}$. Each microcolony acts as an independent community and may contain a variety of bacterial species $^{31}$. Bacteria that are located in the center of the microcolony usually live in a strict anaerobic environment, while others at the periphery of the microcolony are exposed to a more aerobic environment ${ }^{22}$. Therefore, a biofilm is a dynamic structure that can provide a range of environments with respect to nutrient and oxygen concentrations and thus may successfully harbor a diverse bacterial population ${ }^{31}$ To sustain these bacterial populations, a series of fluid channels exist between microcolonies to provide nutrients and oxygen required for normal bacterial growth and to facilitate outward movement of bacterial metabolites, waste products, and enzymes ${ }^{14,32,38}$. Additionally, each bacterial microcolony uses chemical signals to create a primitive communication system within the biofilm, a perfect niche for bacterial propagation and existence $e^{33,33,34}$. 


\section{Development of Dental Plaque}

The growth and development of dental plaque occurs in a four-phase process: initial attachment, rapid growth, steady state and detachment to the planktonic phase ${ }^{32}$.

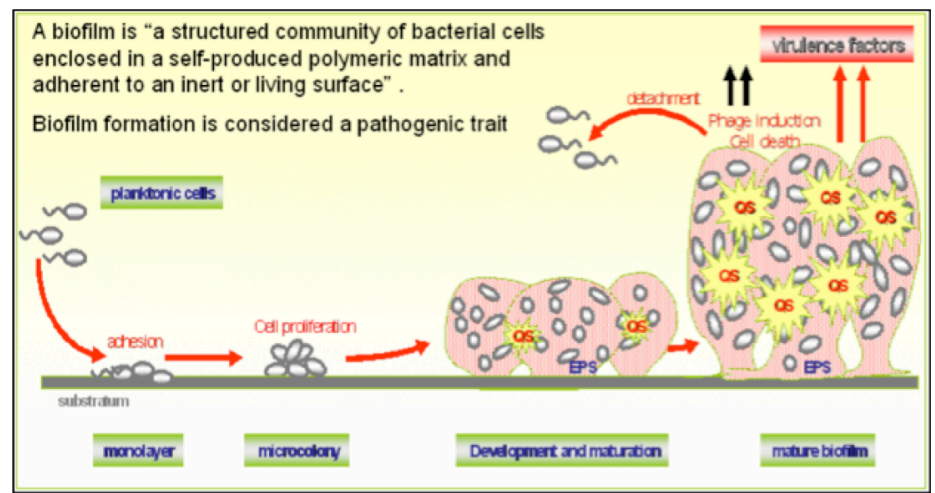

Figure 1: Schematic of biofilm formation.

\section{Initial Attachment}

The initial attachment of bacteria commences after the formation of the salivary pellicle. The pellicle is a thin coating of salivary proteins that adhere to the tooth surface within minutes after tooth eruption or cleaning. The pellicle is composed of albumin, glycoproteins, acidic proline-rich proteins, mucins, cell debris, amylase, lysozyme and sialic acid ${ }^{32,38}$. The pellicle provides a sticky base to support further colonization and propagation of bacteria. Acidic phosphoproteins and proline-rich proteins that aid in colonization of bacteria on to the tooth surfaces33 mediate the initial interaction between the pellicle and the bacteria. In addition to the presence of pellicle, other environmental cues that can influence biofilm formation include low $\mathrm{pH}$, changes in 
osmolarity, and oxygen. The early plaque forming bacteria or the initial colonizers are generally Gram-positive cocci, which primarily comprise streptococcal species ${ }^{32,33,34}$.

\section{Rapid Growth Phase}

Once microorganisms have established a foothold on the tooth surface, they undergo a series of changes. Common adaptations that have been observed include the expression of large quantities of exopolysaccharides that may protect the biofilm and lead to biocide resistance ${ }^{32,33,34}$ The biofilm grows through the attachment of new bacteria through a process of coaggregation ${ }^{17,25,26}$. Coaggregation is driven by specific receptor-ligand interactions that allow new bacterial colonizers to adhere to the previously attached cells and results in increased complexity of the microbial community ${ }^{17,25,26}$. A detailed knowledge of these mechanisms of bacterial attachment and co-adhesion could highlight mechanisms that may be exploited to control the pattern of biofilm formation ${ }^{32,33,34,38}$. For example, analogs could be synthesized that block adhesin-receptor attachment or co-adhesion or alternatively, chemical modification of the colonizing surface could make them less conducive to microbial colonization.

\section{Steady State Phase and Detachment}

As plaque matures in the subgingival pocket, the host mounts an inflammatory response to the microbial challenge and the flow of gingival crevicular fluid (GCF) is increased $^{32,38}$. The GCF not only delivers components of host defense but also serves as a continuous source of glycoproteins and co-factors that provide nutrients for the growing 
microorganisms ${ }^{38}$. In addition, bacterial microcolonies produce degradative enzymes such as endotoxins and lipoteichoic acid that promote an inflammatory response in the gingival tissue ${ }^{34,38}$. Furthermore, the inflammatory host response and increased secretion of GCF leads to a transient increase in the local $\mathrm{pH}$. This increase in $\mathrm{pH}$ favors the growth of anaerobic bacteria such as Prevotella intermedia and P. gingivalis ${ }^{34,38}$. As gingivitis progresses to periodontitis, the microflora can become even more diverse ${ }^{34,38}$. Periodontitis results in tissue damage, which is manifested clinically as attachment loss. Tissue damage results from the activity of the subgingival microflora and indirectly from the release of lysosomal enzymes during phagocytosis or by the production of cytokines that stimulate resident connective tissue cells to release metalloproteinases.

Detachment to the planktonic phase can occur by a variety of active or passive processes. For example, some organisms may express enzymes that degrade the extracellular matrix leading to cell dispersion, while other organisms may reduce the expression of enzymes that are required for biosynthesis of the matrix. Portions of the mature biofilm may also simply slough off and colonize elsewhere.

\section{Implication for the Etiology of Periodontal Diseases}

There are two main hypotheses that explain the role of plaque bacteria in disease ${ }^{19,20}$. First, the "Specific Plaque Hypothesis" proposes that out of the diverse species that exist in dental plaque, only specific species are actively involved in causing disease even if these species are present in low abundance ${ }^{11,19,20,31,30,39}$. Consistent with this, specific organisms such as $P$. gingivalis, $T$. forsythia, and $T$. denticola have all been strongly associated with adult periodontitis ${ }^{4,5,8,10,23,35}$. Furthermore, recent studies also suggest that $P$. gingivalis may play a pivotal role in disrupting host-microbe homeostasis 
and function as a "keystone" pathogen even when present at low abundance in a complex multispecies biofilm ${ }^{28,29,30}$. These studies further indicate that by altering the host response, $P$. gingivalis induces changes in microbial populations in the biofilm leading to uncontrolled inflammation and tissue damage. However, the Specific Plaque Hypothesis cannot adequately explain the absence of the putative pathogens in some cases of disease nor the presence of these pathogenic organisms in healthy patients ${ }^{19}$. In contrast, the "Non-Specific Plaque Hypothesis" purports that many of the heterogeneous mixture of organisms in plaque could play a role in disease, and that disease is a result of the overall interaction of the plaque microflora with the host ${ }^{19}$. It is well established that plaque mediated diseases has multi factorial etiology and a variety of organisms are involved in its progression. Therefore, the specific plaque theory is puzzling, however it does demonstrates some specificity with respect to disease causing organisms. Consequently, a modified hypothesis was proposed which suggested that changes in environmental factors lead to a shift in the resident microflora resulting in microbial dysbiosis ${ }^{19}$. The occurrence of potentially pathogenic species as minor members of the resident plaque microflora would be consistent with this proposal ${ }^{19}$. In health, these organisms would be weakly competitive and mostly be suppressed by intermicrobial antagonism, so that they would comprise only a small percentage of the plaque microflora and would not be significant clinically $^{19}$. Microbial specificity in disease would be due to the fact that the new environmental conditions would activate only a certain group of microorganisms. It is a basic tenet of microbial ecology that a major change to an ecosystem produces a corresponding disturbance to the stability of the resident microbial community ${ }^{19}$. 


\section{Significance of Porphyromonas gingivalis and Streptococcus gordonii Interaction in}

\section{Dental Plaque Biofilm Formation}

Previous work suggests that the adherence of $P$. gingivalis to oral streptococci is an initial event that facilitates $P$. gingivalis colonization of the oral cavity ${ }^{8,9}$. Adherence is driven by a protein-protein interaction between the minor fimbrial antigen (Mfa1) of $P$. gingivalis and antigen I/II (AgI/II) of specific streptococcal species ${ }^{5,8,9,10,12}$. This interaction is mediated by a specific motif in $\mathrm{AgI} / \mathrm{II}$, designated $\mathrm{BAR}^{8,9}$. A synthetic peptide representing BAR potently inhibited the formation of $P$. gingivalis/S. gordonii biofilms in vitro $\left(\mathrm{IC}_{50}=1.3 \mu \mathrm{M}\right)^{8,9,10}$ and significantly reduced $P$. gingivalis virulence in mice that harbor $S$. gordonii when administered simultaneously with $P$. gingivalis infection ${ }^{9}$. These results suggest that BAR peptide blocks $P$. gingivalis colonization of the oral biofilm and may represent an effective therapy to limit recolonization of the oral cavity by $P$. gingivalis after professional prophylaxis. However, a limitation of this potential therapeutic approach is that BAR can only be transiently administered. In addition, while BAR potently inhibits the formation of two species biofilms, it is less effective in disrupting preformed biofilms or more complex communities, which required a higher concentration (i.e., $\mathrm{IC}_{50}=3.6 \mu \mathrm{M}$ ) ${ }^{18}$ and/or prolonged exposure to BAR (i.e., $>60$ minutes $)^{10,7}$. Together, these data suggest that BAR is more effective inhibiting the initial association of $P$. gingivalis and streptococci than disrupting established complex biofilms $^{8,10,18}$. This represents a potential limitation for developing the peptide as a therapeutic for clinical evaluation in humans. Therefore, the goal of this study was to 
develop a method to deliver higher localized concentrations of BAR to the oral cavity to improve BAR effectiveness. Our hypothesis is that nanotechnology may be applied to develop novel non-toxic, poly(lactic-co-glycolic acid; PLGA) nanoparticle (NP) delivery vehicles that increase BAR effectiveness by promoting multivalent surface interactions of BAR with P. gingivalis.

\section{Nano-sized Technology in Advanced Therapeutics}

In recent times, many therapeutic agents have been developed to treat or prevent dental caries and periodontal disease - the two major oral biofilm-associated infections ${ }^{2}$. Traditionally these therapeutic agents have been comprised of antimicrobials that are

delivered to target tissues via oral, subcutaneous or local delivery routes ${ }^{40,27}$. When administered via oral doses, these agents are often destroyed either by enzymes in saliva or during intestinal transit resulting in decreased efficacy ${ }^{50,51}$. Moreover, uncontrolled levels of antimicrobials may lead to concentration spikes resulting in serious side effects and toxic reactions ${ }^{40,27}$. On the other hand, localized drug delivery vehicles including strips, gels and antimicrobial membranes have difficulty accessing the periodontal pockets and resisting recolonization by pathogens, rendering them only partially successful ${ }^{2}$. In contrast to these technologies, delivering antimicrobial molecules via NPs may circumvent many of the challenges mentioned above, thereby producing more effective therapeutics ${ }^{27}$.

NP drug delivery systems offer many advantages over conventional prophylaxes or therapeutics. One advantage of NPs is that their small size enables them to more effectively penetrate barriers and allow for drug accumulation at target sites, resulting in 
enhanced treatment efficiency ${ }^{40}$. NPs have been developed using a variety of materials including metals, ceramics and polymers ${ }^{40,2,1}$. Among several biomaterials, particles made of colloidal gold, iron oxide crystals, hydroxyapatite and silver have been used as antimicrobial agents to prevent dental caries ${ }^{2,1}$. The proposed mechanism of these antibacterial metallic particles is believed to arise from an electrostatic attraction of positively-charged NPs with the negative charge of the bacterial cell membrane ${ }^{1}$. Furthermore, NPs have been investigated for a range of applications including incorporation into dentures, orthodontic adhesive materials and dental resin composites for preventing secondary caries ${ }^{2}$. Other novel systems based on silica have been investigated for anti-biofilm properties ${ }^{2}$. In particular, the use of nitric-oxide-releasing silica NPs to kill biofilm-based microbial cells has recently been investigated ${ }^{2}$. The rapid diffusion of NO may result in enhanced penetration of oral biofilm and thereby, improved anti-biofilm properties ${ }^{2}$. Although the development and the application of nanotechnology have shown immense promise, there have been considerable concerns regarding the potential toxicity associated with metallic NP accumulation in different tissues and organs ${ }^{1}$. To circumvent the challenge of metal cytotoxicity, polymeric NPs have been developed to provide safer and more durable options for drug delivery ${ }^{55}$. In addition, they offer biocompatibility and flexible tuning of physical properties to achieve desired dosages and drug release profiles ${ }^{27}$.

\section{Polymeric Nanoparticles}

Synthetic and natural polymeric NPs have been extensively researched as potential vehicles for drug delivery ${ }^{49}$. Synthetic polymers have the advantage of high purity over natural polymers and may be less likely to evoke an immune response (i.e., 
less immunogenic) ${ }^{40,27}$. Among the variety of synthetic options, poly(lactic acid) (PLA), poly(E-caprolactone) (PCL), polyethyleneimine, and poly(glycolic acid) (PGA) are extensively used in preventing oral biofilms because of their biodegradability and biocompatibility ${ }^{27}$. Among the different polymeric materials, poly(lactic-co-glycolic acid) (PLGA) has attracted considerable attention due to its FDA approval for human therapy ${ }^{27}$. Furthermore, PLGA NPs have well described formulations that can deliver a variety of agents, e.g. hydrophilic or hydrophobic small molecules or macromolecules ${ }^{27}$. Currently, PLGA NPs have been investigated for their use in bone loss in severe periodontitis ${ }^{2}$. Another interesting use of PLGA NPs is in photodynamic therapy, which is a novel alternative to conventional antimicrobials ${ }^{2}$. Photodynamic therapy works on the concept that a photosensitive agent, which absorbs light, can be preferentially incorporated into bacteria and subsequently activated by light. Activation leads to the generation of singlet oxygen and free radicals that are cytotoxic to bacterial cells ${ }^{2}$. For this, PLGA NPs are coupled with photosensitive methylene blue (MB) ${ }^{2}$. PLGA/MB NPs have proven to be effective against various Gram positive and Gram-negative bacteria associated with endodontic and periodontal infections ${ }^{2}$. Furthermore, dexamethasone/PLGA NPs have been extensively studied for their osteoblastic differentiation in periodontal disease ${ }^{2}$. In summary, PLGA NPs provide a biocompatible, non-immunogenic, biologically stable carrier that can encapsulate and/or present on its surface a wide range of biologically active molecules of therapeutic significance ${ }^{2,27}$. Even though additional studies are required to understand the behavior of particles in preventing oral infections, it is important to note that these polymeric NPs are a promising alternative to conventional antimicrobials ${ }^{27}$. 


\section{CHAPTER 2}

\section{HYPOTHESIS AND SPECIFIC AIMS}

Therapeutic approaches that target specific periodontal pathogens or groups of organisms are lacking. Currently, treatment of periodontal disease involves the removal of plaque from the gingival pocket (with possible antibiotic treatment) and if necessary, gingival surgery to reduce pocket depth. To our knowledge, no therapeutic approach exists that promotes host-biofilm homeostasis by limiting pathogen colonization of the biofilm or recolonization after prophylaxis or treatment. To develop an approach that specifically targets pathogen interactions, this project builds upon our previous discovery of a peptide that specifically inhibits $P$. gingivalis colonization of the oral biofilm. We seek to develop peptide delivery PLGA-NPs that not only target $P$. gingivalis, but also deliver BAR to niches in the oral cavity where it will be most effective. We anticipate that these targeted NPs will deliver BAR at higher localized concentrations to specific niches in the oral cavity or microbiome. While tissue targeted NPs have been used against a variety of pathologies, their application and targeting to specific organisms and niches in the oral microbiome represents a novel approach to combat periodontal disease.

\section{Specific Research Hypothesis}

Surface-modified NPs will facilitate multivalent interactions between BAR and the minor fimbrial antigen leading to increased inhibition of $P$. gingivalis adherence to streptococci relative to equimolar amounts of free BAR peptide. 


\section{Specific Aims}

To compare the inhibitory potency of BAR-NPs with soluble BAR we will:

1. Synthesize PLGA NPs that are surface-modified with BAR peptide to facilitate multivalent interaction with $P$. gingivalis.

2. Quantify the density of BAR peptide on the NP surface to optimize the concentration of BAR surface modification.

3. Compare the efficacy of BAR-NPs with the molar equivalent of free BAR peptide using dual and three biofilm model systems. 


\section{CHAPTER 3}

\section{MATERIALS AND METHODS}

\section{Peptide Synthesis}

The BAR peptide used in this study, is shown in Table 1. The peptide is comprised of residues 1167 to 1193 of the SspB (Antigen I/II) protein sequence of $S$. gordonii $^{16}$. The peptide containing a covalently attached biotin at its $\mathrm{N}$-terminus was synthesized by BioSynthesis, Inc. (Lewisville, TX) and was obtained at more than $85 \%$ purity.

Table 1: Sequence of BAR peptide.

\begin{tabular}{|c|c|}
\hline Peptide & Peptide Sequence \\
\hline BAR & $\mathrm{NH}_{2}$-LEAAPKKKVQDLLKKANITVKGAFQLFS-OH \\
\hline
\end{tabular}

To assess the level of BAR present on the NP surface, biotin-BAR was also synthesized that contained 6-carboxyfluorescein (Flc) covalently attached to the epsilon amine of the lysine residue underlined in Table 1 to generate BAR-Flc. For functional controls with free peptide, BAR without biotin or fluorophore was utilized. 


\section{Growth of Bacterial Strains}

P. gingivalis strain ATCC 33277 was grown in Trypticase soy broth media (TSBY media) (Difco) supplemented with $0.5 \%(\mathrm{w} / \mathrm{v})$ yeast extract, $1 \mu \mathrm{g} / \mathrm{ml}$ (final concentration) menadione, and $5 \mu \mathrm{g} / \mathrm{ml}$ (final concentration) hemin. Twenty milliliters of medium was reduced for $24 \mathrm{hr}$ under anaerobic conditions consisting of $10 \% \mathrm{CO}_{2}, 10 \% \mathrm{H}_{2}$, and $80 \%$ $\mathrm{N}_{2}$. Next, $P$. gingivalis was inoculated into the medium and grown for $48 \mathrm{hr}$ at $37^{\circ} \mathrm{C}$ under anaerobic conditions. S. gordonii DL-1 was cultured aerobically without shaking in brain-heart infusion (BHI) broth supplemented with $1 \%$ yeast extract for $16 \mathrm{hr}$ at $37^{\circ} \mathrm{C}$.

\section{Synthesis of Avidin-Palmitate Conjugates}

To obtain BAR-modified PLGA NPs, the NP surfaces were modified with avidinpalmitate to attach biotinylated BAR. Avidin-palmitate was conjugated as previously described by Fahmy and Saltzman. Briefly, $100 \mathrm{mg} / 8 \mathrm{ml}$ solution of avidin was made in $2 \%(\mathrm{w} / \mathrm{v})$ sodium deoxycholate $(\mathrm{NaDC})$ in $\mathrm{PBS}$ and warmed to $37^{\circ} \mathrm{C} .4 .5 \mathrm{mg} / 2 \mathrm{ml}$ solution of palmitic acid-NHS (PA-NHS, Sigma) was prepared in $2 \%(\mathrm{w} / \mathrm{v}) \mathrm{NaDC}$ and sonicated until well-mixed. Two milliliters of the above made PA-NHS solution was added dropwise to the reaction vial containing avidin, and reacted overnight at $37^{\circ} \mathrm{C}$. The following day, the reaction was dialyzed in $1200 \mathrm{~mL}$ of $0.15 \%(\mathrm{w} / \mathrm{v}) \mathrm{NaDC}$ in PBS heated to $37^{\circ} \mathrm{C}$ using a 3500 molecular weight cut off (MWCO) dialysis tubing to remove free PA-NHS. After overnight dialysis at $37^{\circ} \mathrm{C}$, complexed avidin-palmitate was transferred to a storage vial from the dialysis cassette and stored at $4^{\circ}$ 


\section{Nanoparticle Synthesis}

Unmodified and surface-modified PLGA NPs, encapsulating the fluorescent dye Coumarin 6 (C6) for binding and internalization studies were synthesized and characterized as broadly depicted in Figure 2.

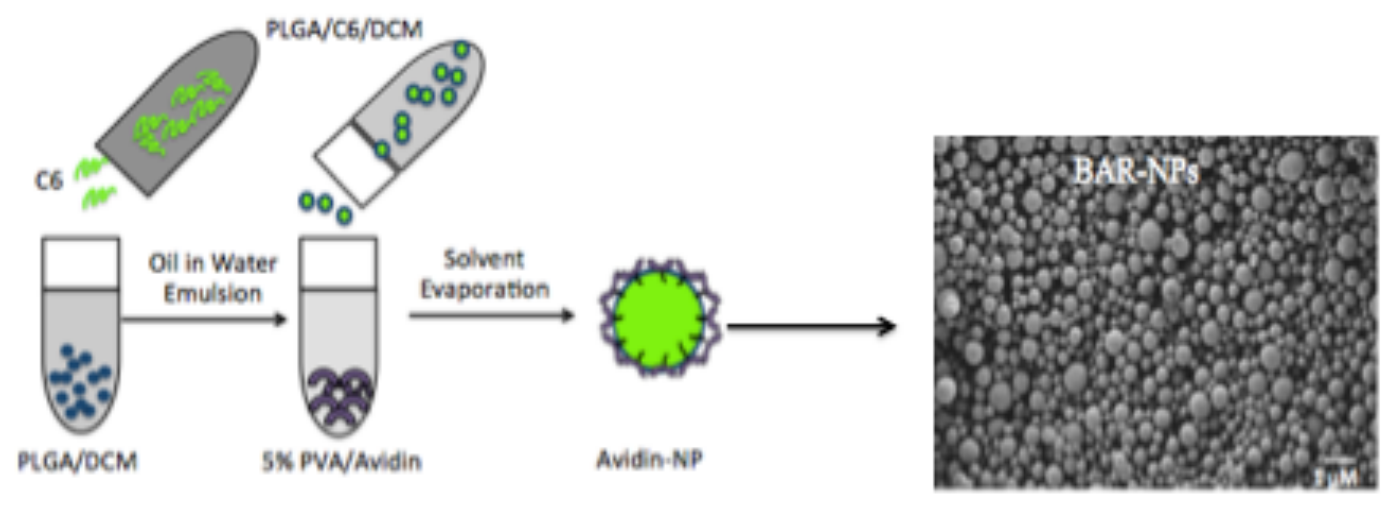

Figure 2: Overview of NP synthesis with an example of the resulting NP morphology analyzed with scanning electron microscopy $(\mathrm{SEM}) .{ }^{*}$ Scale bar $=1 \mu \mathrm{m}$.

\section{BAR-Modification of C6 NPs}

C6 NPs were synthesized using an oil-in-water (o/w) single emulsion technique ${ }^{31}$. Briefly, C6 was encapsulated in 100-200 mg poly(lactic-co-glycolic acid) (PLGA) carboxyl-terminated polymer $\left(0.55-0.75 \mathrm{dL} / \mathrm{g}, \quad\right.$ LACTEL $\left.^{\circledR}\right)$. C6 was dissolved in methylene chloride (DCM) overnight at a concentration of $15 \mu \mathrm{g}$ C6 per mg of PLGA. In parallel, $200 \mathrm{mg}$ PLGA crystals were dissolved in $2 \mathrm{ml}$ of DCM overnight. The following day, the PLGA/DCM solution was vortexed while adding $200 \mu$ of the prepared C6 DCM solution. The PLGA/DCM/C6 solution was sonicated to attain a uniform solution. Next, $2 \mathrm{ml}$ of 5\% (w/v) polyvinyl alcohol (PVA) solution was mixed with $2 \mathrm{ml}$ of 10 $\mathrm{mg} / \mathrm{ml}$ avidin-palmitate to obtain a well-mixed solution. To create the single emulsion, 2 
$\mathrm{mL}$ PLGA/DCM/C6 solution was added dropwise to $4 \mathrm{ml} \mathrm{PVA/avidin-palmitate} \mathrm{under}$ vortexing and subsequent sonication. The residual DCM was evaporated by adding the NP solution to $50 \mathrm{~mL}$ of $0.3 \% \mathrm{PVA}$ for $3 \mathrm{hr}$ while mixing. After solvent evaporation, the $50 \mathrm{ml} \mathrm{NP}$ solution was transferred to tubes and centrifuged at $13,000 \mathrm{rpm}$ at $4^{\circ} \mathrm{C}$ to wash NPs, prior to BAR-peptide conjugation. The supernatant was discarded and the pelleted NPs were resuspended in $9 \mathrm{ml}$ of $\mathrm{diH}_{2} \mathrm{O}$. The resuspended NPs were incubated for $30 \mathrm{~min}$ on a benchtop rotator with biotinylated BAR peptide at a molar ratio of 3:1 BAR:avidin (18.5 nmol/mg) in PBS. After conjugation, the NPs were centrifuged at 13,000 rpm and the supernatant was discarded. The NPs were resuspended in $20 \mathrm{ml} \operatorname{diH}_{2} \mathrm{O}$ and centrifuged twice to remove any remaining unbound BAR peptide. After the three washes, the NPs were suspended in $9 \mathrm{ml}$ of $\mathrm{diH}_{2} \mathrm{O}$, transferred to a $10 \mathrm{ml}$ cryotube, frozen in $-80^{\circ} \mathrm{C}$ for $3 \mathrm{hr}$ and subsequently lyophilized. All NPs were stored at $-20^{\circ} \mathrm{C}$ after synthesis. Unmodified C6 NPs were prepared similarly, however 5\% (v/v) PVA alone was added instead of PVA/avidin-palmitate solution.

\section{$\underline{\text { Nanoparticle Characterization }}$}

Particle size and morphology were determined using scanning electron microscopy (SEM). Dry NPs were mounted on carbon tape and sputter coated with gold under vacuum. Average particle diameter and size distribution were determined from SEM images of at least 400 particles per batch using image analysis software (ImageJ, National Institutes of Health). Zeta potential and dynamic light scattering (DLS) were measured with a Zetasizer Nano ZS (Malvern) in $\mathrm{diH}_{2} \mathrm{O}$ to determine particle charge and hydrated diameter. NPs with zeta potential values ranging from $+25 \mathrm{mV}$ to $-25 \mathrm{mV}$ 
typically have high degrees of stability, indicating less potential for NP aggregation.

\section{Functional Characterization}

As described below, indirect and direct methods were used to quantify the density of BAR peptide on the NP surface.

1. Indirect: The binding of biotin-PEG-FITC to both avidin-NPs and BAR-NPs was measured (Figure 3).

2. Direct: The binding of fluorescently-labeled BAR peptide to avidin-NPs was measured (Figure 4).

\section{Indirect Characterization: Biotin-PEG-FITC Reaction}

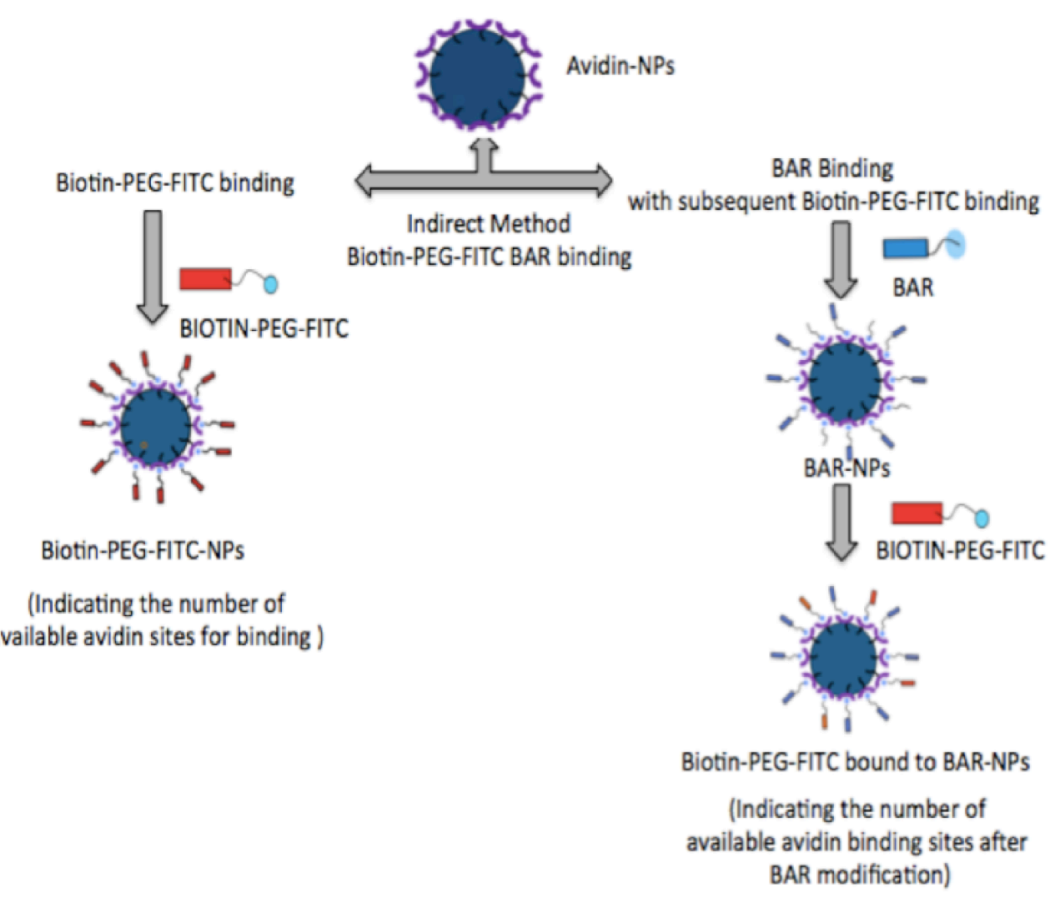

Figure 3: Schematic of the indirect method of NP characterization. Avidin-NPs and BAR-NPs were reacted with saturating concentrations of Biotin-PEG-FITC and NP associated fluorescence was determined. The fluorescence values were converted to an amount of PEG-FITC in both cases and the obtained values were 
Avidin-NPs (20 mg) were synthesized and aliquoted to a $15 \mathrm{ml}$ tube. These NP swere reacted with $18.5 \mathrm{nmol} / \mathrm{mg}$ of biotin-PEG-FITC for $1 \mathrm{hr}$ on a rocker platform in the dark. PEG3400 was used to quantify binding indirectly since it is similar in molecular weight to biotinylated BAR (3400 vs. 3329 Daltons). The concentration of biotin-PEG-FITC used in these reactions (i.e., $18.5 \mathrm{nmol} / \mathrm{mg}$ ) was determined by first calculating the total number of available biotin binding sites on surface-modified avidin, with the assumption that each avidin molecule has 2 available biotin binding sites, and then adding biotin-PEG-FITC at a molar ratio of 3:1 biotin-PEG-FITC: biotin binding sites. After conjugation, the NPs were washed twice with $\mathrm{diH} 2 \mathrm{O}$ by centrifugation at $15,000 \mathrm{rpm}$. After synthesis, the washed particles were frozen, lyophilized and stored at $-20^{\circ} \mathrm{C}$. The following day, the biotin-PEG-FITC labeled NPs were suspended in freshly prepared 1X PBS (10 $\mathrm{mM} \mathrm{NaH}_{2} \mathrm{PO}_{4}, 137 \mathrm{mM} \mathrm{NaCl}$, and $2.7 \mathrm{mM} \mathrm{KCl}, \mathrm{pH}$ 7.4) at 1 $\mathrm{mg} / \mathrm{mL}$ and subsequently diluted 1:2, 1:5 and 1:10-fold in PBS. Samples (100 $\mu$ each) were then transferred into a microtiter plate in triplicate.

A standard curve of biotin-PEG-FITC was obtained by making serial dilutions of a $1 \mathrm{mg} / \mathrm{ml}$ biotin-PEG-FITC stock solution to generate a concentration range of 0.002 to $5 \mu \mathrm{g} / \mathrm{ml}$ biotin-PEG-FITC. The diluted NP samples and standards were measured for fluorescence at $488 \mathrm{~nm}$. The amount of bound biotin-PEG was determined from the standard curve generated with biotin-PEG-FITC. This identified the density of biotinPEG-FITC on the NP surface resulting from a given set of reaction conditions and also identified the concentration of biotin-PEG-FITC required to saturate the avidin present on the NP surface. Next, another aliquot of avidin-modified NPs was conjugated with biotinylated BAR and the resulting BAR-NPs were subsequently incubated with a 
saturating concentration of biotin-PEG-FITC (i.e., 18.5 nmol of biotin-PEG-FITC per 1 mg NPs). NP-associated fluorescence was determined as above and the amount of bound biotin-PEG-FITC was determined from the standard curve. Total BAR modification was calculated with the following equation: [biotin-PEG-FITC associated with avidin-NPs] [biotin-PEG-FITC associated with BAR-modified NPs]. This difference represents the amount of BAR conjugated to the NP surface.

\section{Direct Characterization: Binding of Fluorescently-Labeled BAR to Avidin-NPs}

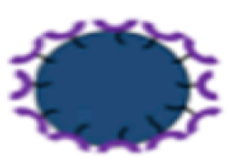

Avidin-NPs

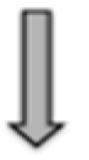

Direct Method of Fluorescently Labeled BAR (BAR-Flc)

binding reaction

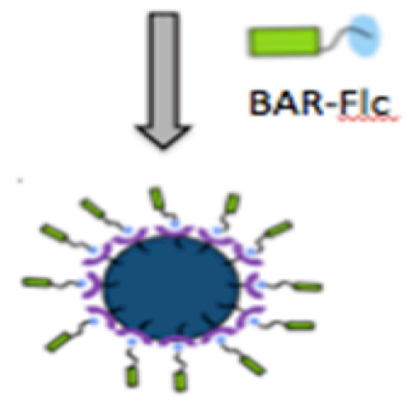

BAR-FlC-NPS

Figure 4: Schematic of the direct characterization method. Avidin-NPs were reacted with increasing concentrations of fluorescently BAR-Flc and compared to a standard of known labeled BAR concentrations to quantify labeled BAR binding on the NP surface. 
The second approach that was used to quantify BAR binding was to directly measure BAR binding to avidin-NPs. This was accomplished using biotinylated BAR in which an internal lysine was labeled with 6-carboxyfluorescein Flc, (see Table 1). Avidin-NPs $(5 \mathrm{mg})$ were aliquoted to eppendorf tubes and mixed with increasing concentrations (3-, 6-, 9-, 18- fold molar access of BAR) $(18.5-111.2 \mathrm{nmol} / \mathrm{mg} \mathrm{NP})$ of fluorescently labeled BAR (BAR-Flc) for $45 \mathrm{~min}$ on a rocker platform in the dark. After conjugation, the NPs were washed twice with $\mathrm{diH}_{2} \mathrm{O}$ after centrifugation at 15,000 rpm. The washed samples were frozen, lyophilized and stored at $-20^{\circ} \mathrm{C}$ after synthesis. On day 2, NPs from each eppendorf tube were aliquoted and suspended in 1X PBS to attain suspensions of $1 \mathrm{mg} \mathrm{NP} / \mathrm{ml}$. The resulting samples were transferred to a microtiter plate in triplicate. After conjugation with BAR-Flc, total NP-associated fluorescence was calculated from a standard curve obtained from known BAR-Flc concentrations. Both the indirect and direct approaches described above allowed us to quantify the amount of BAR peptide bound to the NP surface and enabled us to optimize the synthesis and conjugation conditions to obtain maximal binding of BAR to the NP surface. Surfacemodification using avidin-biotin linkages represent an established and efficient method to conjugate our novel peptide to the NP surface ${ }^{56}$.

\section{P. gingivalis Binding Assay}

The adherence of BAR-NPs to P. gingivalis was assayed using BAR-modified NPs that encapsulated the fluorescent probe C6. P. gingivalis was cultured as previously described and to establish a uniform cell concentration across all samples, $P$.gingivalis suspensions were adjusted to a final optical density of 0.4 . Subsequently, a $1 \mathrm{ml}$ aliquot 
of $P$. gingivalis cells was transferred into eppendorf tubes and mixed with increasing concentrations of BAR-modified C6 encapsulated NPs $(1 \mu \mathrm{g} / \mathrm{ml}, 2.5 \mu \mathrm{g} / \mathrm{ml}, 5 \mu \mathrm{g} / \mathrm{ml}$, and $10 \mu \mathrm{g} / \mathrm{ml}$ ) for $45-60$ mins on a rocker platform in the dark. Negative controls for this experiment consisted of: 1) P. gingivalis incubated with unmodified C6 NPs and 2) BAR-modified C6 NPs incubated in buffer without $P$. gingivalis to evaluate nonspecific binding. After incubation, the samples were centrifuged at $5600 \mathrm{rpm}$ for $5 \mathrm{~min}$ and the supernatant was discarded to remove the unbound particles. The remaining cells were resuspended in 1X PBS. One hundred microliters of each sample were transferred to a microtiter plate and the cell bound fluorescence was measured at $488 \mathrm{~nm}$.

\section{Dual Species Biofilm}

Cultures of $P$. gingivalis and $S$. gordonii were obtained as previously described. S. gordonii DL-1 cells were harvested by centrifuging a $12 \mathrm{ml}$ culture of $S$. gordonii at $5600 \mathrm{rpm}$ for $5 \mathrm{~min}$. The supernatant was discarded and the cell pellet was resuspended in $1 \mathrm{ml}$ of $1 \mathrm{X}$ PBS. S. gordonii was labeled with $20 \mu \mathrm{l}$ of $10 \mathrm{mM}$ hexidium iodide (5 $\mathrm{mM}$, Molecular Probes, Eugene, OR) for $15 \mathrm{~min}$ at room temperature on a rocker platform protected from light. After incubation the labeled samples were centrifuged at $5600 \mathrm{rpm}$ for $5 \mathrm{~min}$, the supernatant was discarded, and the cells were resuspended in 1 $\mathrm{ml}$ of $1 \mathrm{X}$ PBS. Following this, the optical density (O.D) was measured at $600 \mathrm{~nm}$ from ten-fold diluted cultures of $S$. gordonii to determine cell count.

For all experiments, the optical density of S. gordonii cells was adjusted to 0.8 for uniformity of the S. gordonii cell amounts in each well. After adjusting the optical density, $1 \mathrm{ml}$ of $S$. gordonii cells was added to a 12 well culture plate containing a 
sterilized micro-coverslip in each well. The 12 well cell culture plate was wrapped in aluminum foil to protect the labeled cells from light and placed on a rocker platform in the anaerobic chamber for $24 \mathrm{hr}$.

P. gingivalis cultures used for biofilm formation were optimized using a similar approach. Briefly, $12 \mathrm{ml}$ of $P$. gingivalis cells were centrifuged for $5 \mathrm{~min}$ at $5600 \mathrm{rpm}$. The supernatant was discarded and the cell pellet was resuspended in $1 \mathrm{ml}$ of prereduced 1X PBS. P. gingivalis cells were labeled with $20 \mu 1$ of carboxyfluoresceinsuccinylester (4 mg/ml, Molecular Probes). Cells were incubated with the fluorescent dye for $30 \mathrm{~min}$ and protected from light. Following incubation, cells were centrifuged at $10000 \mathrm{rpm}$ for $1 \mathrm{~min}$ and the supernatant was discarded to remove the unbound fluorescent dye. The pelleted cells were resuspended in $1 \mathrm{ml}$ of pre-reduced $1 \mathrm{X}$ PBS.

Previous experiments showed that the optimal inoculum for P. gingivalis was a cell suspension that was adjusted to an optical density of 0.4 . For biofilm inhibition assays using BAR-NPs, the initial optical density $(600 \mathrm{~nm})$ was adjusted to 0.8 and the cell suspension was subsequently diluted with an equal volume of the BAR-NP suspension to generate a final O.D. $600 \mathrm{~nm}$ of 0.4 . For biofilm inhibition experiments, BAR-NPs or soluble BAR peptide was pre-incubated with labeled $P$. gingivalis cells at peptide concentrations ranging from 0 to $10 \mu \mathrm{g} / \mathrm{ml}$ at $25^{\circ} \mathrm{C}$ for $30 \mathrm{~min}$ before transferring to the appropriate wells. The 12 well cell culture plate was covered with aluminum foil and incubated for 18-24 hr in an anaerobic chamber.

Following incubation, the supernatant was removed from the wells of the 12 well cell culture plate and the cells were washed with pre-reduced 1X PBS to remove nonadherent bacterial cells. The cells were subsequently fixed with $4 \%(\mathrm{w} / \mathrm{v})$ using 
paraformaldehyde, excess paraformaldehyde was removed, and the cells were washed with pre-reduced $1 \mathrm{X}$ PBS. The coverslip was then mounted on to a glass slide using Prolong Gold anti-fade reagent and viewed using confocal laser scanning microscopy.

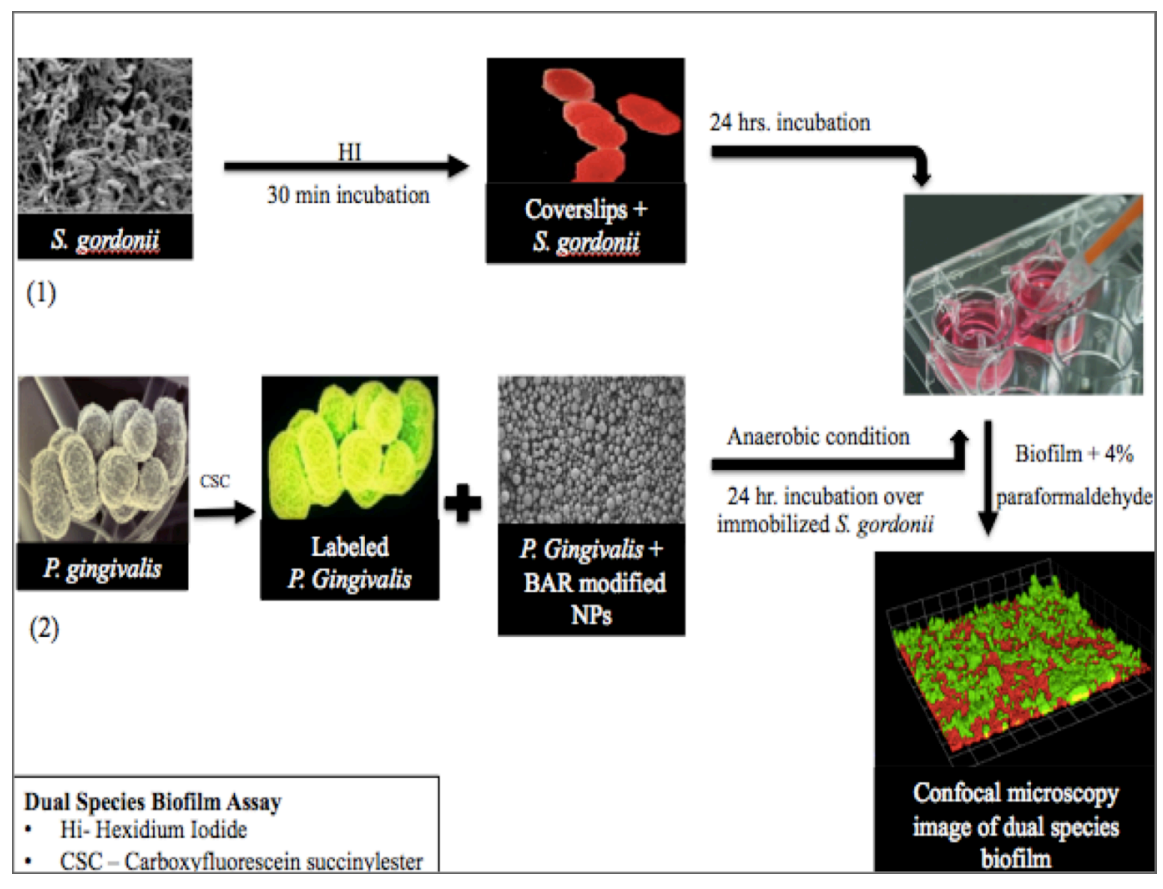

Figure 5: Dual Species Biofilm Assay: (1) S. gordonii cells were labeled with Hexidium iodide, added to micro-coverslips in a 12 well cell culture plate, and incubated. (2) After removal of the supernatant, $P$. gingivalis cells labeled with carboxyfluorescein 5, 6- succinyl ester were incubated with the BAR-modified NPs, added to the micro-coverslips, and incubated anaerobically. After $24 \mathrm{hr}$ incubation, the coverslips were fixed and mounted onto slides and visualized using Olympus Fluoview FV500 Laser Scanning Microscopy. 


\section{Confocal Microscope}

P. gingivalis-S. gordonii biofilms were visualized using an Olympus Fluoview 500 confocal laser scanning microscope (Olympus, Pittsburgh, PA). The slides were viewed using an argon laser for visualization of FITC-labeled $P$. gingivalis and the HeNe-G laser to visualize hexidium iodide- labeled streptococci. P. gingivalis binding was determined from 30 to 60 randomly chosen frames using FluoView Software. Z-stack images of the biofilms were obtained using a z-step size of $0.7 \mu \mathrm{m}$ and images were analyzed with the Volocity image analysis software.

\section{Image Analysis}

After obtaining the images from confocal microscopy, the resulting $\mathrm{z}$-stack images were processed and reconstructed into 3D images using the Volocity software. Images were imported into Volocity as multiple Tiff-files. Uniform filters were used to remove noise from the images and were further analyzed to quantify the extent of $P$. gingivalis binding. The image brightness and contrast was adjusted equally for all frames, and a snapshot of the image was captured. Next, the ratio of green to red fluorescence was determined. Each peptide concentration was analyzed in triplicate and 3 independent frames were measured for each well. The mean and variation (SD) between samples was determined using ANOVA. The variation was considered statistically significant when $\mathrm{P}<0.05$. 


\section{CHAPTER 4}

\section{RESULTS}

\section{Nanoparticle Synthesis and Characterization}

Previous studies have demonstrated the utility of coupling peptides to NP surfaces via avidin-biotin ligands (Av-ligand) ${ }^{41}$. In this study both the unmodified and BAR-NPs led to NPs of comparable size (Figure 6A). Analysis of SEM images shows the average NP diameters of $98 \pm 28$ and $134 \pm 28 \mathrm{~nm}$ for unmodified and BAR-NPs, respectively. As expected, the presence of BAR on the NP surface did not significantly change the size of the NPs $(\mathrm{P}>0.05)$. Furthermore, no change was seen in the characteristic texture and morphology after surface conjugation, relative to unmodified NPs. NP surface charge was measured by zeta potential, and DLS was used to measure the hydrodynamic diameter (Figure 6B). Average hydrodynamic diameters determined via DLS were $298 \pm 13 \mathrm{~nm}$ and $329 \pm 10 \mathrm{~nm}$ for the unmodified and BAR-NPs, respectively. As expected the diameters measured for hydrated NPs using DLS were slightly higher than the diameters of unhydrated NPs analyzed with SEM.

NP surface charge and hydrodynamic diameter were used to predict the long-term stability and surface-modification of the NPs. Zeta potential values were measured for NPs with avidin and BAR surface modification (Figure 6C). Unmodified NPs exhibited a negative charge of $-25 \mathrm{mV}$. Addition of avidin to the NPs produced more positive zeta 
potentials, which correlated with increased avidin density on the NP surface. When BAR was added to avidin-NPs, the zeta potential was slightly, but not significantly more positively charged, correlating with increased ligand conjugation. This is consistent with the net positive charge of BAR. Furthermore, there was a significant difference in zeta potential between the unmodified and avidin-NP groups and unmodified and BAR-NP groups ( $\mathrm{P}<0.01)$. There was no significant difference between avidin-NPs and BAR-NPs.

(A)
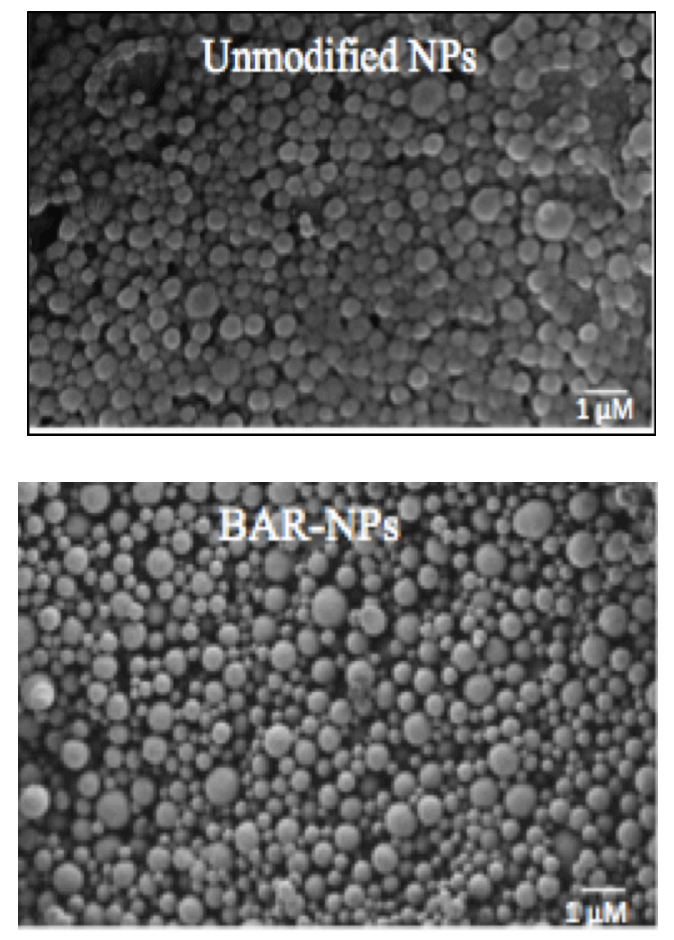
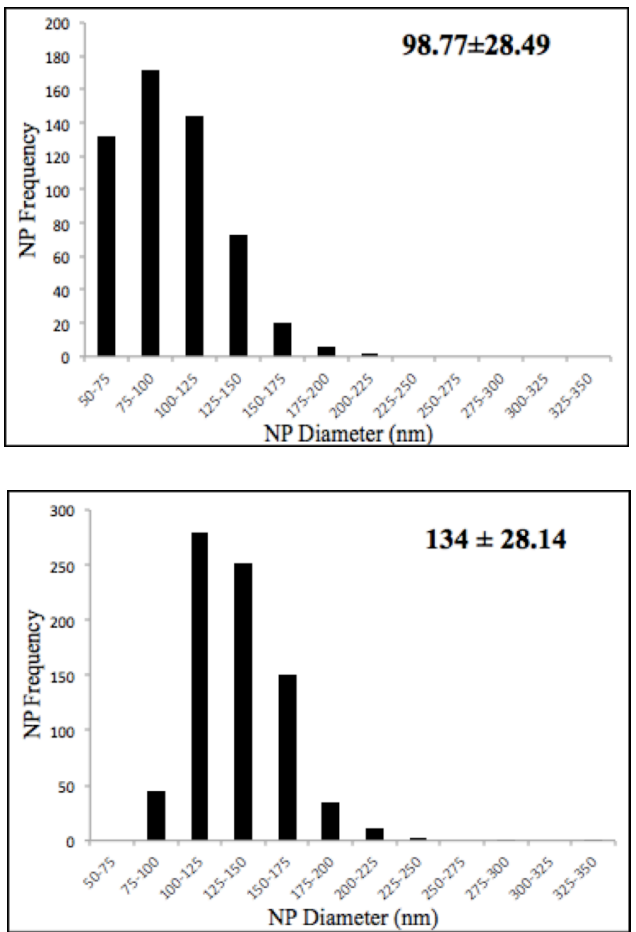

(B)

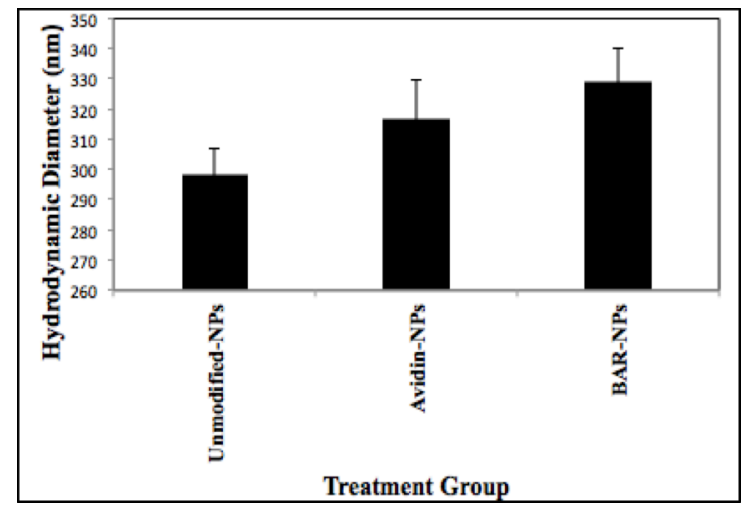


(C)

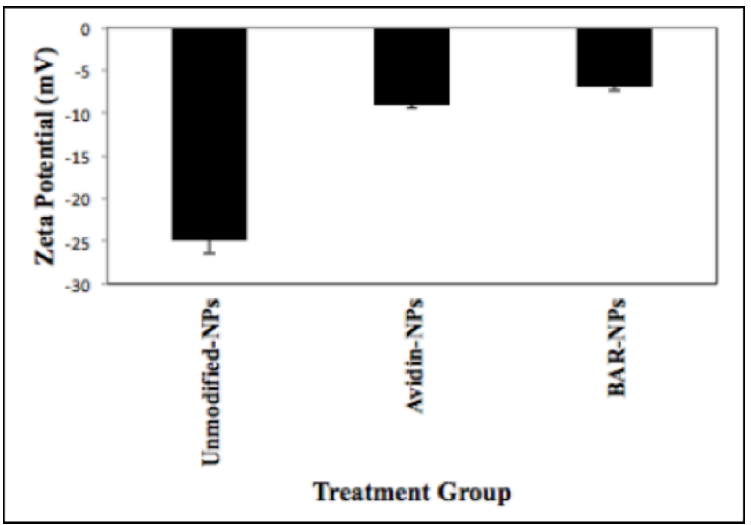

Figure 6: (A) SEM images of unmodified and BAR-NPs and their corresponding distribution of NP diameter. (B) DLS values of NP hydrodynamic diameters. (C) Zeta potential values of all NPs. The surface charge on unmodified and BAR-NPs was statistically significant $(\mathrm{P}<0.01)$

\section{Surfae Modification Efficacy and Functionality of PLGA-NPs}

To determine and optimize the amount of BAR peptide incorporated on the surface of the PLGA NPs, we utilized two different detection methods, an indirect method (biotin-PEG-FITC binding reaction) and a direct method (fluorescently-labeled BAR binding). The results from both the direct and indirect assays allowed us to optimize the synthesis and conjugation conditions to obtain maximal binding of BAR to the NP surface.

\section{Quantification of the Total Biotin Binding Sites.}

The incorporation of avidin on avidin-NPs was determined using the microBCA assay. The estimate of the number of available biotin binding sites was important for subsequent BAR modification. The microBCA indicated that $3.1 \mathrm{nmol} / \mathrm{mg}$ of avidin was 
present on the surface per milligram NPs which was similar to the amount of avidin added to the synthetic reaction. This indicates that $100 \%$ of the input avidin $(3.0$ $\mathrm{nmol} / \mathrm{mg}$ ) was incorporated on the NP surface. Next the amount of avidin was converted into molecules of avidin per NP. This conversion indicated that 3940 molecules of avidin were present per NP. Although avidin has 4 biotin binding sites, we assumed that each molecule would only have 2 accessible biotin binding sites and the remaining 2 sites would be inaccessible due to steric hindrance. Hence, we calculate that $3.1 \mathrm{nmol} / \mathrm{mg}$ (3940 molecules/NP) of avidin would bind $6.2 \mathrm{nmol} / \mathrm{mg}$ (7880 molecules/NP) of BAR.

\section{Indirect (Biotin-PEG-FITC Binding Experiment)}

In this experiment, we compared the fluorescence of avidin-NPs and BAR-NPs that were both treated with biotin-PEG-FITC to determine the number of available biotin binding sites before and after conjugation with biotinylated BAR. Biotin-PEG-FITC is comprised of PEG with a molecular weight of 3400 to closely match the molecular weight of BAR (3326 Da). Biotin-PEG-FITC was conjugated with both avidin-NPs and BAR-NPs at a ratio of 3:1 biotin-PEG-FITC: biotin-binding sites $(18.5 \mathrm{nmol} / \mathrm{mg}$ biotinPEG-FITC). Fluorescence of the resulting NPs was measured in triplicate and the mean fluorescence was quantified. The fluorescence values obtained were converted to an amount of PEG-FITC using a standard curve derived from increasing concentrations of biotin-PEG-FITC. Subtracting the level of biotin-PEG-FITC incorporated into BAR-NPs from the amount incorporated into avidin-NPs using Equation 1 allowed us to indirectly determine the number of BAR peptides present on the surface of BAR-NPs. Table 2 shows the number of biotin-PEG-FITC molecules per NP with the respective surface 
modification. As expected, we found the surface density of biotin-PEG-FITC on BARNPs to be significantly less than biotin-PEG-FITC bound to avidin-NPs. Using a 3-fold (3:1) molar excess of biotin to avidin, $4.05 \mathrm{nmol} / \mathrm{mg}$ of biotin-PEG-FITC (5170 molecules/NP) was bound to avidin-NPs occupying 65 percent of the total biotin binding sites on the avidin-NP surface (Table 2). In contrast, when avidin-NPs were first conjugated with biotin-BAR and reacted biotin-PEG-FITC, $0.12 \mathrm{nmol} / \mathrm{mg}$ of biotin-PEGFITC (149 molecules/NP) was incorporated on the surface of the BAR-NPs, occupying only $2 \%$ of the biotin binding sites, suggesting that $98 \%$ of the available biotin binding sites on avidin-NPs were occupied by biotin-BAR after conjugation (Table 2).

Table 2: Biotin-PEG-FITC surface density of avidin-NPs and BAR-NPs. The number of avidin molecules per NP was determined by the microBCA assay. It was assumed that each molecule of avidin subsequently bound two molecules of Biotin-PEG-FITC.

\begin{tabular}{|c|c|c|c|c|}
\hline Sample & $\begin{array}{c}\text { No. of Molecules of } \\
\text { Avidin per NP Obtained } \\
\text { from microBCA }\end{array}$ & $\begin{array}{c}\text { \# Avidin Binding Sites } \\
\text { per NP Available for } \\
\text { PEG-FITC Binding }\end{array}$ & $\begin{array}{c}\text { \# Biotin-PEG-FITC } \\
\text { molecules/NP }\end{array}$ & $\begin{array}{c}\text { \% Biotin-PEG-FITC } \\
\text { incorporation }\end{array}$ \\
\hline Avidin-NPs & 3940 & 7880 & 5170 & 65 \\
\hline BAR-NPs & 3940 & 7880 & 149 & 2 \\
\hline
\end{tabular}

\section{Direct (Fluorescently Labeled BAR Binding Experiment)}

To more directly determine the level of BAR incorporated after conjugation of avidinNPs, we titrated avidin-NPs with 3-, 6-, 9- and 18- fold molar excess (18.5 - 111.2 $\mathrm{nmol} / \mathrm{mg}$ ) of fluorescently-labeled BAR (BAR-Flc). NPs were reacted with concentrations higher than $18.5 \mathrm{nmol} / \mathrm{mg}$ as the 3 -fold excess used in indirect binding experiment indicated that higher concentration was needed for saturating the available avidin binding sites. NPs were incubated with BAR-Flc for $1 \mathrm{hr}$, washed, lyophilized, and 
fluorescence was quantified as previously described. The incorporation of BAR-Flc on avidin-NPs was directly related to concentration of BAR-Flc added. As shown in Figure 8 , we observed that saturation of BAR-Flc binding occurred with an input concentration of $37.1 \mathrm{nmol} / \mathrm{mg}$ (6- fold molar excess of calculated biotin binding sites) indicating that at this input concentration, all of the available biotin sites were bound with BAR-Flc. Mean fluorescence values did not significantly increase when NPs were conjugated with higher concentrations of BAR-Flc (Figure 8). Using a 3-fold (3:1) molar excess of BAR to avidin, $3.85 \mathrm{nmol} / \mathrm{mg}$ of BAR-Flc (4910 molecules/NP) was bound to avidin-NPs occupying $62.3 \%$ of the total biotin binding sites on the avidin-NP surface (Table 3). At the saturation concentration of $37.1 \mathrm{nmol} / \mathrm{mg}$ ( 6 fold molar excess of calculated biotin binding sites), $7.42 \mathrm{nmol} / \mathrm{mg}$ of BAR-Flc (9460 molecules/NP) was incorporated on the surface of the avidin-NPs, occupying $100 \%$ of the biotin binding sites. Furthermore, BAR-flc binding did not significantly increase when NPs were conjugated with higher concentration of BAR-Flc $(55.6-111.2 \mathrm{nmol} / \mathrm{mg})$

Table 3: Biotin-Flc surface density of avidin-NPs and BAR-NPs. The number of avidin molecules per NP was determined by the microBCA assay. The concentration of BAR-Flc obtained from the direct characterization was converted into the number of bound BARFlc per NP.

*Assuming that each molecule of avidin have two binding sites.

\begin{tabular}{|c|c|c|c|c|}
\hline $\begin{array}{c}\text { BAR-FIc Input } \\
\text { Concentration }\end{array}$ & $\begin{array}{c}\text { No. of Molecules of Avidin } \\
\text { per NP obtained from } \\
\text { microBCA }\end{array}$ & $\begin{array}{c}\text { \# Avidin binding sites per } \\
\text { NP available for BAR-Flc } \\
\text { Binding }\end{array}$ & $\begin{array}{c}\text { \# BAR-Flc } \\
\text { molecules/NP }\end{array}$ & $\begin{array}{c}\text { \% BAR-Flc } \\
\text { incorporation }\end{array}$ \\
\hline $18.5 \mathrm{nmol} / \mathrm{mg}(3: 1)$ & 3940 & 7880 & 4910 & 62.9 \\
\hline $37.2 \mathrm{nmol} / \mathrm{mg}(6: 1)$ & 3940 & 7880 & 9460 & $100^{*}$ \\
\hline $55.62 \mathrm{nmol} / \mathrm{mg}(9: 1)$ & 3940 & 7880 & 9310 & $100^{*}$ \\
\hline $111.2 \mathrm{nmol} / \mathrm{mg}(18: 1)$ & 3940 & 7880 & 9360 & $100^{*}$ \\
\hline
\end{tabular}




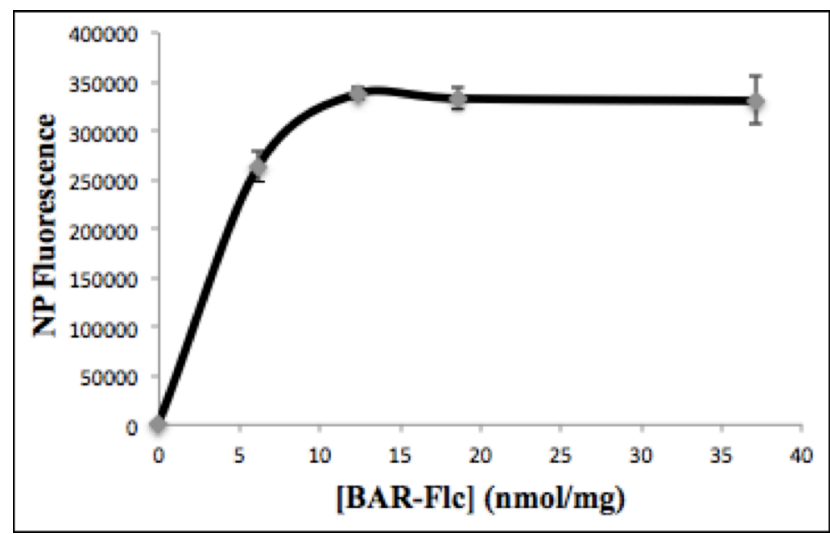

Figure 7: Saturation curve of BAR-Flc. Avidin-NPs were reacted with a 3-, 6-, 9-, 18 fold molar excess of BAR-Flc (18.5 - $111.2 \mathrm{nmol} / \mathrm{mg} \mathrm{NP})$ and the NP bound Fluorescence was determined and plotted.

To determine if BAR-NPs were functional, we evaluated BAR-NP binding to $P$. gingivalis. BAR-NPs encapsulating the fluorophore C6 were incubated with $P$. gingivalis cells and cell-bound fluorescence was measured. In these experiments, the BAR-NP concentration was determined using total NP mass. As shown in Fig. 9, BAR-NPs bound to $P$. gingivalis cells in a dose-dependent manner. These results demonstrated proof-ofconcept that uniformly sized BAR-NPs interact with $P$. gingivalis in a dose-dependent manner

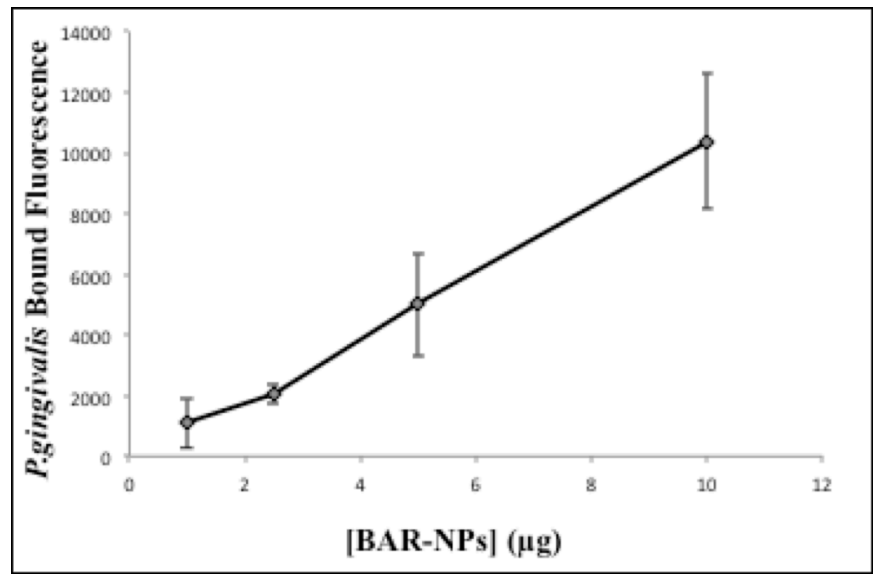

Figure 8: Dose Dependent binding of BAR-NPs with encapsulated C6 to $P$. gingivalis. 


\section{BAR Inhibits Formation of $P$. gingivalis Biofilms}

To determine if BAR-NPs competitively inhibit $P$. gingivalis adherence to streptococcal cells and prevent biofilm development, $P$. gingivalis biofilms were formed on immobilized streptococci in the presence of increasing concentrations of BAR-NPs for $24 \mathrm{hr}$. Previous studies showed that soluble BAR had an $\mathrm{IC}_{50}(50 \%$ inhibitory concentration) of $1.3 \mu \mathrm{M}$. Therefore, in these experiments, the amount of BAR on the surface of BAR-NPs was calculated using the direct binding results and sufficient amounts of NPs to deliver BAR peptide concentrations ranging from 0.3 to $1.7 \mu \mathrm{M}$ were tested and compared with similar concentrations of free soluble BAR.

$P$. gingivalis adherence to the immobilized streptococci was visualized using confocal scanning microscopy and the ratio of green $(P$. gingivalis) and red $(S$. gordonii) fluorescence was quantified using Volocity image analysis software. For control reactions, $P$. gingivalis was incubated with streptococci in the presence of buffer alone. The representative images of biofilms formed in the presence of BAR-NPs or soluble BAR are shown in Figure 10. As summarized in Table 3, BAR-NPs exhibited dose dependent inhibition of biofilm formation with the ratio of green to red fluorescence being significantly reduced $(\mathrm{P}<0.01)$ at all concentrations. The striking result was that BARNPs more potently inhibit $P$. gingivalis adherence than soluble BAR. 


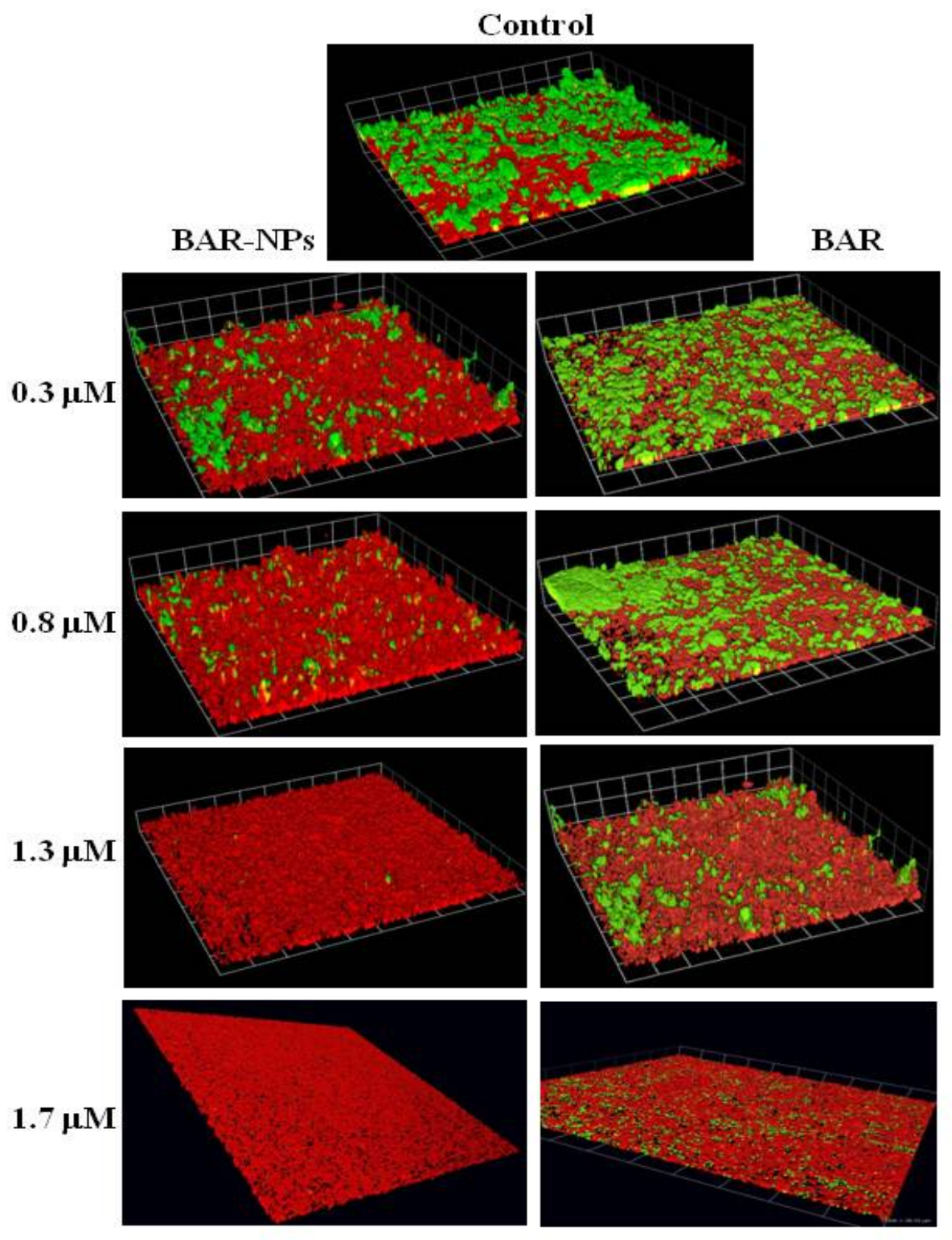

Figure 9: Comparison of BAR and BAR-NP inhibition of $P$. gingivalis and $S$. gordonii 
Table 3: Dose response of free BAR peptide and BAR-NPs in P. gingivalis-S. gordonii dual species biofilms.

\begin{tabular}{|c|c|c|c|c|c|}
\hline & Control & $\mathbf{1 . 7} \boldsymbol{\mu M}$ & $\mathbf{1 . 3} \boldsymbol{\mu M}$ & $\mathbf{0 . 8} \boldsymbol{\mu M}$ & $\mathbf{0 . 3} \boldsymbol{\mu M}$ \\
\hline BAR peptide & $0 \%$ & $79.3 \%$ & $50 \%$ & $6.9 \%$ & $3.3 \%$ \\
\hline BAR-NPs & $0 \%$ & $95.7 \%$ & $93.7 \%$ & $81.9 \%$ & $57.3 \%$ \\
\hline
\end{tabular}

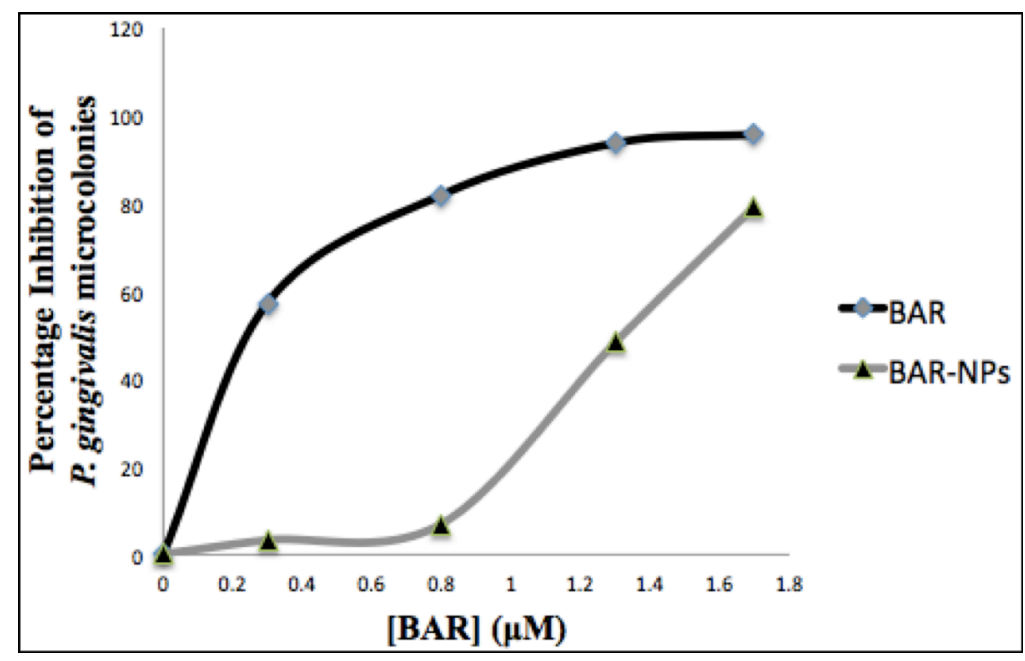

Figure 10: $P$. gingivalis inhibition plot of BAR-Flc and soluble BAR obtained from the dual species biofilm assay. P. gingivalis was reacted with increasing concentration $(0.3-1.7 \mu \mathrm{M})$ of BAR-NPs and the percentage inhibition of $P$. gingivalis microcolonies were determined and plotted.

These results show that NPs surface-modified with BAR peptide more potently inhibit $P$. gingivalis adherence to $S$. gordonii $\left(\mathrm{IC}_{50} \sim 0.29 \mu \mathrm{M}\right)$ than soluble $\left(\mathrm{IC}_{50}=1.3\right.$ $\mu \mathrm{M})$, indicating that BAR-NPs are approximately 4.5 times more potent than soluble BAR. This suggests that BAR-NPs may promote multivalent interaction with $P$. gingivalis and that surface modified NPs may represent a viable mechanism to deliver higher localized concentrations of BAR peptide to the biofilm. Together, the results 
provide proof-of-principle that targeted antimicrobial NPs can be utilized to control the complex biofilm associated with periodontal disease. 


\section{CHAPTER 5}

\section{DISCUSSION}

The human oral cavity presents a hostile environment to microorganisms as a result of the constant flow of saliva that contains numerous antimicrobial agents ${ }^{11}$. The early colonizers protect themselves from these conditions by forming multispecies biofilms with other resident organisms ${ }^{11}$. The periodontal pathogen $P$. gingivalis faces different challenges in colonizing the oral cavity since it is an obligate anaerobe that is acid-sensitive and requires hemin as an essential growth factor ${ }^{11}$. Therefore, its primary niche is the subgingival pocket but before establishing itself in that niche, it must first survive in relatively aerobic supragingival environment ${ }^{11,23,24}$. To accomplish this, $\mathrm{P}$. gingivalis interacts with the primary colonizer $S$. gordonii that provides a physiologically compatible local environment for $P$. gingivalis ${ }^{11}$. Since this interaction is one of the initial events that leads to $P$. gingivalis colonization of the oral cavity, it represents an ideal target for therapeutic intervention to limit $P$. gingivalis colonization and potentially reduce adult periodontitis ${ }^{11,22,23}$. Previous studies have been successful identifying the mechanisms of this interaction and adherence between $P$. gingivalis and $S$. gordonii $^{11,23,24}$. It was found that the Mfal of P. gingivalis interacted with SspB of $S$. gordonii. Furthermore, P. gingivalis showed binding specificity with streptococcus gordonii and it did not adhere to Streptococcus mutans, which expressed SpaP, a highly conserved homolog of SspB. These studies led to the development of BAR peptide, 
which is derived from the antigen I/II protein of $S$. gordonii and functions as a potent inhibitor of $P$. gingivalis adherence to $S$. gordonii. Corresponding a peptide derived from SpaP of S. mutants showed that it did not interact with Mfa1 of $P$. gingivalis. In addition, BAR significantly reduced $P$. gingivalis virulence in mice that harbor $S$. gordonii when administered simultaneously with $P$. gingivalis infection ${ }^{11,23}$. However, although BAR potently inhibits the formation of two species biofilms, it is less effective in disrupting established biofilms or more complex biofilms, requiring higher concentrations and prolonged exposure to be effective. In this study, it was hypothesized that targeted nanoparticles comprised of an FDA-approved polymer, PLGA, and surface modified with BAR may enhance the potency of the peptide via two mechanisms: 1) by delivering BAR at higher localized concentration to $P$. gingivalis and 2) by promoting a multivalent binding interface to increase the avidity of BAR with $P$. gingivalis.

In this study a reproducible and rapid preparation method was developed to synthesize unmodified and BAR-NPs. Previous studies have demonstrated that avidinbiotin-ligand conjugation provides one of the strongest non-covalent bonds, while offering a flexible, tunable, and efficient method to conjugate and alter ligand density on the NP surface ${ }^{41}$. The synthetic process that was developed resulted in the production of spherical unmodified and BAR-modified NPs with a narrow particle size distribution (size about 100-134 nm). Additionally, we observed a negative surface charge for unmodified NPs but a slightly positive charge for BAR-NPs. This disparity of charge can be explained by the carboxyl groups of PLGA for unmodified NPs and the presence of cationic molecules, i.e., avidin and BAR on the surface of modified $\mathrm{NPs}^{41}$. Furthermore, the zeta-potential values for both unmodified $(-25 \mathrm{mV})$ and BAR-NPs $(-10 \mathrm{mV})$ are in 
agreement with other unmodified and avidin-NP studies, where, unmodified PLGA NPs typically have a negative surface charge and avidin-modified NPs display a more positive surface charge. The statistically significant $(\mathrm{P}<0.01)$ surface charge that we observed between unmodified-NPs and BAR-NPs was attributed to successful conjugation with the positively-charged BAR peptide. For biological experiments, this positive zeta potential may also be beneficial as the positive NP surface charge might facilitate the interaction of NPs with $P$. gingivalis by promoting electrostatic attractions with the negative moieties on the bacterial cell membrane.

To design a NP formulation with maximal levels of BAR peptide, it was important to first quantify the number of avidin molecules present on the NP surface and available for subsequent BAR conjugation. To estimate the number of molecules of avidin per NP, we used the microBCA assay to confirm $100 \%$ incorporation of the input avidin to the NP surface. Although under these conditions, we were able to achieve virtually $100 \%$ incorporation of avidin on the NP surface, we believe that these NPs have greater potential to incorporate more avidin on its surface. One way to confirm this is to determine the level of avidin saturation for the NPs. After quantifying the amount of the avidin, we next calculated the number of biotin binding sites that may be available for ligand binding. Each avidin has four biotin binding sites; however, the binding sites are in close proximity to each other and the NP surface, which may lead to steric hindrance ${ }^{41}$. Hence, we assumed that only 2 biotin-binding sites per avidin molecule would be available for interaction with biotinylated-BAR.

To experimentally determine the ligand concentration required to saturate the available biotin binding sites, we reacted avidin-NPs and BAR-NPs with a 3-fold molar 
excess of biotin-PEG-FITC $(18.5 \mathrm{nmol} / \mathrm{mg})$. Our results show that when biotin-PEGFITC was reacted with avidin-NPs, biotin-PEG-FITC occupied only $65 \%(4.05 \mathrm{nmol} / \mathrm{mg})$ of the available binding sites. This result suggests, that $18.5 \mathrm{nmol}$ biotin-PEG-FITC per $\mathrm{mg}$ of avidin NP is not sufficient to saturate the available binding sites. When avidinNPs were first reacted with $18.5 \mathrm{nmol} / \mathrm{mg}$ biotinylated-BAR and subsequently with biotin-PEG-FITC, only $2 \%$ of the biotin binding sites bound to biotin-PEG-FITC, suggesting that $98 \%$ of the available biotin binding sites were occupied by biotinylated BAR.

Since it was possible in the experiments above that $18.5 \mathrm{nmol}$ biotin-PEG-FITC per mg avidin-NP was insufficient to saturate the biotin binding sites, a direct approach was used to quantify the amount of BAR bound to the NP surface using a fluorescein labeled peptide (BAR-Flc). For these experiments, BAR-Flc was reacted with avidin-NPs at a concentration range of $18.5,37.1,55.6$ and $111.2 \mathrm{nmol} / \mathrm{mg}$ avidin-NPs (representing 3-, 6-, 9-, and 18-fold molar excess of BAR-Flc relative to the calculated biotin binding sites available) and NP bound fluorescence was determined. The results from this experiment were consistent with the indirect assay in that a 3 -fold molar excess (18.5 $\mathrm{nmol} / \mathrm{mg}$ ) of BAR-Flc occupied approximately $62 \%$ of the available biotin sites. We previously assumed that each avidin molecule would only have 2 accessible biotin binding sites. From the microBCA, this assumption would indicate that $3.1 \mathrm{nmol} / \mathrm{mg}$ of avidin incorporated on the NP surface bind $6.2 \mathrm{nmol} / \mathrm{mg}$ of BAR. However, at an input concentration of $37.1 \mathrm{nmol} / \mathrm{mg}$ of BAR-Flc (6- fold molar excess), we discovered 7.4 $\mathrm{nmol} / \mathrm{mg}$ of BAR-Flc was incorporated on the surface of avidin-NPs. This indicated that Avidin-NPs were saturated with BAR-Flc at an input concentration of $37.1 \mathrm{nmol} / \mathrm{mg}$ 
avidin-NPs. Given this result, further conjugation reactions with BAR were carried out using $55.6 \mathrm{nmol}$ of BAR-Flc per mg avidin-NPs and no significant additional BAR-Flc binding was observed. Together these results indicate that the assumption of two biotin binding sites was conservative and that few of the NPs had 3 available binding sites.

To assess the function of BAR-NPs, we compared the ability molar equivalent amounts of BAR peptide carried by BAR-NPs and soluble BAR to inhibit $P$. gingivalis adherence to S. gordonii. As shown in Figure 10, both soluble BAR and BAR-NPs inhibited $P$. gingivalis adherence in a dose dependent manner. However, BAR-NPs more potently inhibited $P$. gingivalis adherence relative to soluble BAR. The $\mathrm{IC}_{50}$ of BARNPs was significantly lower $(<0.3 \mu \mathrm{M})$ than soluble BAR $\left(\mathrm{IC}_{50} 1.3 \mu \mathrm{M}\right)$.

It is reported in many other studies that NPs that bind a large number of ligands show increased drug efficacy by promoting a multivalent binding interface ${ }^{41}$. In our experiments, we believe that BAR-NPs followed a similar mechanism of increased efficacy. In the future, we expect to develop mechanisms to identify the role that ligand number and ligand type plays in multivalent interaction between NP-ligands and a targeted receptor. Though the current approach does not provide comprehensive information about the binding kinetics of synthetic multivalent NPs, our analyses has an impact on the real-world biopharmaceutical development by providing a theoretical framework for designing future NPs that are better suited for targeting other microorganisms in oral biofilms. We also recognize that the etiology of periodontal disease is complex, and although recent evidence suggests that $P$. gingivalis may play an essential role in altering host-microbe homeostasis, other pathogens or pathogen interactions may have a significant impact on disease progression. Therefore, while these 
delivery approaches will be initially applied to target BAR peptide to $P$. gingivalis niches, NPs might have broader applicability for targeting several other oral bacteria. This could be achieved for example, by co-modifying the surface of NPs with several other antimicrobial agents targeting other bacteria in the oral cavity. Furthermore, NPs could be co-modified with cell-surface adhesive proteins to increase retention times of these NPs in the oral cavity.

Our results suggest that BAR-NPs show a striking advantage at low concentrations and result in significantly higher inhibition of $P$. gingivalis adherence to $S$. gordonii than soluble BAR. We believe that the greater efficiency of BAR-NPs at lower concentrations can be helpful for the future development of therapeutic formulations such as a mouth rinse or chewing gum. In the oral cavity, the constant flow of saliva, the intake of food and water and other factors may reduce the levels of therapeutic NPs (i.e., wash out). Thus, the effectiveness of BAR may be reduced with time and approaches to increase the potency of the peptide. Due to the efficacy of BAR-NPs at both high and low concentrations, relative to soluble BAR, the beneficial activity of BAR may be wellsuited to this open flow environment. Overall, our experiments show that we have a reliable and defined method of modifying NPs with inhibitory peptides. Our results suggest that nanotechnology can be efficiently used to combat oral pathogens and reduce oral diseases. It has been recently established that NPs are a proven platform for numerous infectious disease ${ }^{2}$. Hence the use of NP based drug delivery system to target specific organisms and niches in the oral microbiome represents a novel approach to combat periodontal disease. 
Future studies will focus on developing alternative approaches of NP synthesis which incorporate more avidin per NP thereby further increasing the payload of BAR. Furthermore, assessing the efficacy of BAR-NPs by incorporating changes in the density of BAR surface modification. Furthermore, investigations will focus on the ability of BAR-NPs to reduce $P$. gingivalis virulence using the modified Baker mouse model of periodontitis. Together, the results from these experiments may provide proof-ofprinciple of the efficacy with which surface-modified targeted antimicrobial NPs can be utilized to control the complex biofilm associated with periodontal disease. Furthermore, additional studies will focus on synthesizing and characterizing targeted PLGA NPs that encapsulate BAR to provide an alternative platform that offers prolonged-release of the peptide. Following this, experiments will be done to examine the toxicity of modified and sustained release NPs against human oral gingival and innate immune cells, and methods to formulate NP preparations. The long-term goal is to develop a formulation that can be tested for efficacy in clinical trials. 


\section{REFERENCES}

1. Adeyemi, O. S., \& Sulaiman, F. A. (2015). Evaluation of metal nanoparticles for drug delivery systems. Journal of biomedical research, 29(2), 145.

2. Allaker, R. P. (2010). The use of nanoparticles to control oral biofilm formation.Journal of dental research, 89(11), 1175-1186.

3. Bradshaw, D. J., Marsh, P. D., Watson, G. K., \& Allison, C. (1998). Role of Fusobacterium nucleatum and coaggregation in anaerobe survival in planktonic and biofilm oral microbial communities during aeration. Infection and immunity,66(10), 4729-4732.

4. Brooks, W., Demuth, D. R., Gil, S., \& Lamont, R. J. (1997). Identification of a Streptococcus gordonii SspB domain that mediates adhesion to Porphyromonas gingivalis. Infection and immunity, 65(9), 3753-3758

5. Chung, W. O., Demuth, D. R., \& Lamont, R. J. (2001). Identification of a Porphyromonas gingivalis Receptor for the Streptococcus gordonii SspB Protein. Infection and immunity, 69(12), 7964.

6. Cook, G. S., Costerton, J. W., \& Lamont, R. J. (1998). Biofilm formation by Porphyromonas gingivalis and Streptococcus gordonii. Journal of periodontal research, 33(6), 323-327.

7. Costerton, J. W., Cheng, K. J., Geesey, G. G., Ladd, T. I., Nickel, J. C., Dasgupta, M., \& Marrie, T. J. (1987). Bacterial biofilms in nature and disease. Annual Reviews in Microbiology, 41(1), 435-464.

8. Daep, C. A., Lamont, R. J., \& Demuth, D. R. (2008). Interaction of Porphyromonas gingivalis with oral streptococci requires a motif that resembles the eukaryotic nuclear receptor box protein-protein interaction domain. Infection and immunity, 76(7), 3273-3280.

9. Daep, C. A., Novak, E. A., Lamont, R. J., \& Demuth, D. R. (2011). Structural dissection and in vivo effectiveness of a peptide inhibitor of Porphyromonas gingivalis adherence to Streptococcus gordonii. Infection and immunity, 79(1), 67-74.

10. Daep, C. A., James, D. M., Lamont, R. J., \& Demuth, D. R. (2006). Structural characterization of peptide-mediated inhibition of Porphyromonas gingivalis biofilm formation. Infection and immunity, 74(10), 5756-5762 
11. Dalwai, F., Spratt, D. A., \& Pratten, J. (2006). Modeling shifts in microbial populations associated with health or disease. Applied and environmental microbiology, 72(5), 3678-3684

12. Demuth, D. R., Irvine, D. C., Costerton, J. W., Cook, G. S., \& Lamont, R. J. (2001). Discrete protein determinant directs the species-specific adherence of Porphyromonas gingivalis to oral streptococci. Infection and immunity, 69(9), 5736-5741.

13. Diaz, P. I., Chalmers, N. I., Rickard, A. H., Kong, C., Milburn, C. L., Palmer, R. J., \& Kolenbrander, P. E. (2006). Molecular characterization of subject-specific oral microflora during initial colonization of enamel. Applied and environmental microbiology, 72(4), 2837-2848.

14. Dufour, D., Leung, V., \& Lévesque, C. M. (2010). Bacterial biofilm: structure, function, and antimicrobial resistance. Endodontic Topics, 22(1), 2-16.

15. Eke, P. I., Dye, B. A., Wei, L., Slade, G. D., Thornton-Evans, G. O., Borgnakke, W. S.,\& Genco, R. J. (2015). Update on Prevalence of Periodontitis in Adults in the United States: NHANES 2009 to 2012. Journal of periodontology, 86(5), 611622 .

16. Eke, P., et al. (2012). "Prevalence of periodontitis in adults in the United States: 2009 and 2010." Journal of dental research 91(10): 914-920

17. Grenier, D. (1992). Demonstration of a bimodal coaggregation reaction between Porphyromonas gingivalis and Treponema denticola. Oral microbiology and immunology, 7(5), 280-284

18. Gummadi, N. S. (2013). Peptide Mediated Inhibition of Porphyromonas Gingivalis Dual and Three Species Biofilms (Doctoral dissertation, University of Louisville).

19. Hajishengallis, G., \& Lamont, R. J. (2012). Beyond the red complex and into more complexity: the polymicrobial synergy and dysbiosis (PSD) model of periodontal disease etiology. Molecular oral microbiology, 27(6), 409-419.

20. Hajishengallis, G. (2014). Immunomicrobial pathogenesis of periodontitis: keystones, pathobionts, and host response. Trends in immunology, 35(1), 3-11.

21. Heijl, L., Rifkin, B. R., \& Zander, H. A. (1976). Conversion of chronic gingivitis to periodontitis in squirrel monkeys. Journal of periodontology, 47(12), 710-716 
22. Hojo, K., Nagaoka, S., Ohshima, T., \& Maeda, N. (2009). Bacterial interactions in dental biofilm development. Journal of dental research, 88(11), 982-990.

23. Ikegami, A., Honma, K., Sharma, A., \& Kuramitsu, H. K. (2004). Multiple functions of the leucine-rich repeat protein LrrA of Treponema denticola.Infection and immunity, 72(8), 4619-4627

24. Kassebaum, N. J., Bernabé, E., Dahiya, M., Bhandari, B., Murray, C. J. L., \& Marcenes, W. (2014). Global Burden of Severe Periodontitis in 1990-2010 A Systematic Review and Meta-regression. Journal of dental research, 0022034514552491

25. Kinder, S. A., \& Holt, S. C. (1989). Characterization of coaggregation between Bacteroides gingivalis T22 and Fusobacterium nucleatum T18. Infection and immunity, 57(11), 3425-3433.

26. Kolenbrander, P. E., \& Andersen, R. N. (1989). Inhibition of coaggregation between Fusobacterium nucleatum and Porphyromonas (Bacteroides) gingivalis by lactose and related sugars. Infection and immunity, 57(10), 3204-3209.

27. Kumari, A., Yadav, S. K., \& Yadav, S. C. (2010). Biodegradable polymeric nanoparticles based drug delivery systems. Colloids and Surfaces B: Biointerfaces, 75(1), 1-18.

28. Lamont, R. J., \& Jenkinson, H. F. (2000). Subgingival colonization by Porphyromonas gingivalis. Oral microbiology and immunology, 15(6), 341-349.

29. Lamont, R. J., Hersey, S. G., \& Rosan, B. (1992). Characterization of the adherence of Porphyromonas gingivalis to oral streptococci. Oral microbiology and immunology, 7(4), 193-197.

30. Lamont, R. J., \& Jenkinson, H. F. (2000). Subgingival colonization by Porphyromonas gingivalis. Oral microbiology and immunology, 15(6), 341-349

31. Li, J., Helmerhorst, E. J., Leone, C. W., Troxler, R. F., Yaskell, T., Haffajee, A. D., \& Oppenheim, F. G. (2004). Identification of early microbial colonizers in human dental biofilm. Journal of applied microbiology, 97(6), 1311-1318.

32. Marsh, P. D. (1994). Microbial ecology of dental plaque and its significance in health and disease. Advances in dental research, 8(2), 263-271.

33. Marsh, P. D. (1989). Host defenses and microbial homeostasis: role of microbial infections. J Dent Res, 68, 1567-75.

34. Marsh, P. D. (2006). Dental plaque as a biofilm and a microbial communityimplications for health and disease. BMC Oral health, 6(Suppl 1), S14. 
35. Moore, W. E. C., \& Moore, L. V. (1994). The bacteria of periodontal diseases. Periodontology 2000, 5(1), 66-77.

36. Park, Y., Simionato, M. R., Sekiya, K., Murakami, Y., James, D., Chen, W., \& Lamont, R. J. (2005). Short fimbriae of Porphyromonas gingivalis and their role in coadhesion with Streptococcus gordonii. Infection and immunity, 73(7), 39833989 .

37. Park, J., Mattessich, T., Jay, S. M., Agawu, A., Saltzman, W. M., \& Fahmy, T. M. (2011). Enhancement of surface ligand display on PLGA nanoparticles with amphiphilic ligand conjugates. Journal of Controlled Release, 156(1), 109-115.

38. Rosan, B., \& Lamont, R. J. (2000). Dental plaque formation. Microbes and infection, 2(13), 1599-1607.

39. Sbordone, L., \& Bortolaia, C. (2003). Oral microbial biofilms and plaque-related diseases: microbial communities and their role in the shift from oral health to disease. Clinical oral investigations, 7(4), 181-188.

40. Singh, R., \& Lillard, J. W. (2009). Nanoparticle-based targeted drug delivery.Experimental and molecular pathology, 86(3), 215-223.

41. Steinbach, J. M., Seo, Y. E., \& Saltzman, W. M. (2015). Cell Penetrating PeptideModified Poly (Lactic-co-Glycolic Acid) Nanoparticles with Enhanced Cell Internalization. Acta Biomaterialia. 


\section{CURRICULUM VITAE}

NAME: $\quad$ Paridhi Kalia

ADDRESS: Dept. of Oral Immunology and Infectious Disease University of Louisville School of Dentistry

501 South Preston Louisville, KY 40202

DOB: $\quad$ Anand, Gujarat State, India. - May 26, 1989

EDUCATION

\& TRAINING

B.D.S, Dental Surgery

Bhavnagar University

2007-12

\section{PROFESSIONAL}

SOCIETIES

American Association for Dental Research (AADR)

Jan 2015 - Ongoing

International Association for Dental Research (IADR)

Jan 2015 - Ongoing

National Student Research Group (NSRG)

Jan 2015 - Ongoing

American Association for Advancements in Science (AAAS)

March 2014 - Ongoing

Biomedical Engineering Society

Feb 2014 - Ongoing 


\section{PRESENTATIONS}

Research!Louisville, Louisville, KY

Nov 2015, Sep 2014

Poster Presentation: Synthesis and Functional Evaluation of PeptideModified Poly(Lactic-co-Glycolic Acid) Nanoparticles to Inhibit Porphyromonas gingivalis Biofilm Formation

23 $3^{\text {rd }}$ Indiana University Research Day, Indianapolis, IN April 2015

Poster presentation: Synthesis and Functional Evaluation of PeptideModified Poly(Lactic-co-Glycolic Acid) Nanoparticles to Inhibit Porphyromonas gingivalis Biofilm Formation

IADR/AADR/CADR General session and exhibition, Boston, MA March 2015

Poster presentation: Synthesis and Functional Evaluation of PeptideModified Poly(Lactic-co-Glycolic Acid) Nanoparticles to Inhibit Porphyromonas gingivalis Biofilm Formation

$20^{\text {th }}$ Hinman Student Research Symposium, Memphis, TN Oct $31^{\text {st }}-$ Nov $2^{\text {nd }} 2014$ Poster Presentation: Synthesis and Functional Evaluation of PeptideModified Poly(Lactic-co-Glycolic Acid) Nanoparticles to Inhibit Porphyromonas gingivalis Biofilm Formation

Gyandeep Interstate Dental Convention, Vadodara, Gujarat, India March 2012

Paper Presentation: Nano Medicine: Developing Smarter Periodontal Therapeutics

$4^{\text {th }}$ Indo-Australian Conference on Biomaterials and Drug Delivery System, Anand, Gujarat, India

Feb 2011

Poster Presentation: Novel Biomaterials in Periodontal Regeneration 